\title{
Origen geográfico de los solicitantes de asilo y concesiones de Protección internacional en España entre 2008 y 2018
}

\author{
Geographical origin of asylum seekers and international \\ protection concessions in Spain between 2008 and 2018
}

\author{
Rubén C. Lois-González ${ }^{1}$ \\ Universidad de Santiago de Compostela, España \\ $F^{c o}$ Javier García-Delgado ${ }^{2}$ \\ Universidad de Huelva, España \\ Jesús Felicidades-García ${ }^{3}$ \\ Universidad de Huelva, España \\ María de-la-Rosa-Martínez ${ }^{4}$ \\ Universidad de Huelva, España
}

\section{Resumen}

En 2018 ACNUR cifró en 40 millones los desplazados internos, 25,4 millones los refugiados y 3,1 millones los solicitantes de asilo internacional (ACNUR-España, 2018), suponiendo la mayor crisis de refugiados desde la Segunda Guerra Mundial. Los flujos de desplazados, fundamentalmente de

1 Rubén C. Lois González. Doctor en Geografía. Catedrático de Análisis Geográfico Regional y VicePresidente de la UGI, Departamento de Geografía, Universidad de Santiago de Compostela. Correo electrónico:rubencamilo.lois@usc.es. D https://orcid.org/0000-0003-4717-1061

2 Fco Javier García Delgado. Doctor en Geografía e Historia. Profesor Titular de Análisis Geográfico Regional, Departamento de Historia, Geografía y Antropología, Universidad de Huelva. Correo electrónico:fcogarci@uhu.es. (D) https://orcid.org/0000-0001-8863-4179

3 Jesús Felicidades García. Doctor en Geografía e Historia. Profesor Contratado Doctor de Análisis Geográfico Regional, Departamento de Historia, Geografía y Antropología, Universidad de Huelva. Correo electrónico:jesusfe@uhu.es (D) https://orcid.org/0000-0002-4194-8768

4 María de la Rosa Martínez. Graduada en Trabajo Social. Investigadora G. I. Instituto de Desarrollo Local, Universidad de Huelva. Correo electrónico: mariadelarosamartinez@outlook.com.

(iD https://orcid.org/0000-0002-0996-0855 
sur a norte y de este a oeste y en frontera, han aumentado en las dos últimas décadas, al tiempo que se han producido cambios en la legislación de los Estados receptores para limitar el derecho de asilo y la acogida de refugiados, como es el caso de los miembros de la UE. Las restricciones, factores y causas en origen (guerra, discriminación, persecución de parte de la población, etc.), han generado mudanzas en la procedencia de los solicitantes, pero también de las concesiones de figuras de protección internacional. En España es posible analizar a través de fuentes oficiales (Ministerio del Interior) los cambios habidos en la procedencia de las solicitudes de asilo y en las concesiones de protección internacional en el período 2008-2018, lo que permite establecer correlaciones entre causas y factores internos y externos. En su conjunto, se observan cambios en el origen de los solicitantes debido a la extensión de los conflictos armados (Siria, Irak), la crisis institucional (Venezuela) o las restricciones en países tradicionales de asilo (El Salvador, Honduras), y cómo están cambiando las preferencias de acogida en España como Estado receptor.

Palabras-clave: Protección internacional, refugiados, inmigración, España, asilo.

\begin{abstract}
In 2018, UNHCR numbered 40 million internally displaced persons, 25.4 million refugees and 3.1 million international asylum seekers (UNHCR-Spain, 2018), effectively equating to the largest refugee crisis since World War II. The flow of displaced individuals, mainly from south to north and from east to west, and across international borders, has increased in the past two decades whilst legislation changes occur in the receiving states as a response to limit the right of asylum and refugee reception, as is the case in EU member states. Restrictions, factors and multiple causes (war, discrimination, population persecution, etc.), not only has generated the displacement of applicants from their countries of origin, but has also modified the nature of concession of international protection. In Spain, it is possible to analyze, through official sources (i.e. Ministry of the Interior), the trend in evolution of the countries of origin as stated in asylum applications and international protection concessions filed during the period 2008-2018, thus facilitating the formulation of correlations between causes and internal and external factors. As a whole, changes of the country of origin of applicants are evidenced as a consequence of the expansion of armed conflicts (Syria, Iraq), institutional crises (Venezuela), restrictions imposed by traditional asylum countries (El Salvador, Honduras), and also the shift in reception preferences emerging in Spain as receiving state.
\end{abstract}

Keywords: International protection; Refugees; Immigration; Spain; Asylum.

\title{
Introducción
}

Los refugiados son personas que tienen un temor fundado a ser perseguidas "por motivos de raza, religión, nacionalidad, pertenencia a un grupo social en particular u opinión política" (ONU, 1951, p. 3). La mayoría de los 28,5 millones de refugiados y solicitantes de protección internacional se encuentran en Estados fronterizos con escenarios de conflicto (Turquía, Uganda, Pakistán, Líbano, Irán), con frecuencia en campamentos miserables con poca seguridad (Hatton, 2016, p. 441). Sin embargo, el 
Rubén C. Lois-González, Fo Javier Garcia-Delgado Jesús Felicidades-García, María de-la-Rosa-Martínez Origen geográfico de los solicitantes de asilo y concesiones de Protección internacional

en España entre 2008 y 2018

grupo más visible (por la acción de los medios de comunicación), aun siendo una minoría, es el de los que buscan refugio en los países desarrollados.

Desde 2015, tras la "crisis de los refugiados", no es necesario recordar el drama de las migraciones forzosas (Hatton, 2016, p. 441), que se ha cotidianizado y deshumanizado en un escenario en el que los países de destino aplican políticas restrictivas y selectivas para la protección internacional de los demandantes de asilo.

El procedimiento de protección internacional es un instrumento administrativo destinado a proteger a los nacionales de otros Estados "en sustitución de las autoridades nacionales" (MI, 2009, p. 9), e incluye tres figuras (ONU, 1951, p. 2): asilo, protección subsidiaria y protección temporal a desplazados y apátridas.

Entre 2008 y 2018, un total de 6,39 millones de solicitudes de asilo (de las cuales 5,70 son solicitantes por primera vez) (Eurostat, 2019) se presentaron en el territorio de la Unión Europea (UE-28). Sin embargo, y a pesar de la idea generalizada (generada por medios de comunicación, redes sociales, partidos políticos, etc.) la protección internacional es muy inferior a la percibida y tiene una escasa incidencia estadística (Ambrosini, 2016, p. 3), limitada a 1,81 millones de decisiones positivas (28,33\% del total de solicitudes) (Eurostat,2019), apenas el 0,35\% de la población comunitaria.

Al tiempo que aumentan los flujos de refugiados y las solicitudes de asilo, se asiste a restricciones en las legislaciones nacionales ${ }^{5}$ de los Estados de acogida (Belloso, 2016b; p.91), lo que motiva que las condiciones propias de cada uno determine las políticas a seguir. De esta forma, una gran parte de la UE-28 se ha negado a recibir refugiados e, incluso, han cuestionado la libre circulación de personas en su territorio (Belloso, 2016b; p. 91).

Esto ha llevado a que diferentes países, incluidos receptores tradicionales de refugiados (Suecia, Alemania o Austria), reclamen una política de asilo comunitaria. El Reglamento de Dublín ${ }^{6}$ establece los criterios y mecanismos de determinación del Estado miembro responsable de examinar una solicitud de asilo presentada por un nacional de un tercer país (MI, 2017, p. 8). 
Ante el desbordamiento y la catástrofe humanitaria (como en la crisis de los refugiados en Siria, aunque no es la única), la UE ha establecido (2015) cuotas de acogida (Belloso, 2016a, p. 91), que en su mayoría han sido incumplidas. El resultado de esta política restrictiva ha dado paso a la discriminación con el establecimiento de campos de internamiento ${ }^{7}$, el cambio en los flujos de refugiados y la firma de acuerdos de readmisión como elemento distorsionador de la política con terceros (Belloso, 2016a, p. 91; Rais, 2016, pp. 46-47).

España, en cumplimiento de las obligaciones contraídas por su adhesión a los tratados y organizaciones internacionales dispone de un sistema de protección internacional. La Comisión Interministerial de Asilo y Refugio (CIAR) está integrada por representantes de los ministerios implicados en los procesos (con competencias en Justicia, Trabajo, Inmigración, Exteriores, Cooperación, Igualdad e Interior) y a sus reuniones se convoca al Alto Comisionado de las Naciones Unidas para los Refugiados (ACNUR).

$\mathrm{Su}$ actividad principal es el examen de las solicitudes de protección internacional admitidas a trámite y la formulación de propuestas de resolución al Ministro del Interior (MI, 2009, p. 9). Estas solicitudes podrán denegarse cuando se den condiciones tales como el reconocimiento previo como refugiado por otro Estado, la procedencia de un tercer Estado considerado seguro o la retirada de una solicitud en un Estado miembro de la UE (MI, 2009, p. 10).

La materialización del asilo (concesiones finales) depende de las causas y factores en origen (los que motivan la salida y otorgan el derecho a la protección) y de los factores de destino (condiciones específicas de los Estados que otorgan la protección).

\section{Causas $y$ factores internos y externos de la protección internacional}

Las Ciencias Sociales han abordado las migraciones internacionales desde diferentes perspectivas, siendo un tema clásico para la Geografía, aunque no exento de dificultades (Consoli, 2015, p. 7). Al tratar el origen

7 Como un instrumento basado en el derecho de protección internacional, la Convención se sostiene en tres principios: no discriminación, no penalización y no expulsión (Peters y Bisley, 2015, p. 3). Ello ha hecho que se presenten solicitudes de asilo para retrasar procesos de expulsión de «inmigrantes económicos», por lo que institucionalmente se plantean estas fórmulas de discriminación a la espera de resoluciones. 
Rubén C. Lois-González, Fo Javier Garcia-Delgado Jesús Felicidades-García, María de-la-Rosa-Martínez Origen geográfico de los solicitantes de asilo y concesiones de Protección internacional

en España entre 2008 y 2018

de los solicitantes de asilo y las nacionalidades a las que se concede la protección internacional, se pueden establecer, a través de las fuentes oficiales: flujos, espacios de emisión y acogida; causas (de salida) y factores internos que determinan la toma de decisiones para la elección del destino; y factores externos (de los Estados de acogida) que explican la prevalencia de concesiones a unas nacionalidades frente a otras.

Las causas internas de salida de los países de origen de los solicitantes de asilo (posteriores refugiados) fueron establecidas por la Convención de Ginebra (ONU, 1951, p. 14), y se relacionan con el temor individual a ser perseguido por diferentes razones (Hatton, 2016, p. 441): raza, religión, nacionalidad (no reconocimiento), opinión política (extensible a amenazas derivadas del desempeño de un cargo, etc.) o pertenencia a un determinado grupo social.

La última puede identificarse con cuestiones de género (Freedman, 2012, p. 45; Charsley y Wray, 2015, p. 404) o contendencias sexuales (Türk, 2013, pp. 5-6) y también pueden determinar la emigración forzosa de grupos de edad concretos, como los niños (Guasch, 2010, p. 13; Consoli, 2015, p. 8).

Estas causas se identifican con factores internos (colectivos) de los países de origen. De un lado, están los factores políticos (básicos para las emigraciones forzadas): falta de libertades individuales (dictaduras, autocracias, sociedades tradicionales), inseguridad individual (Belloso, 2016b, p.99) y, especialmente, conflictos armados o estado de guerra (Hatton y Williamson, 2006, p.250; Abu-Warda, 2007, p.37; Chin y Cortes, 2015, p. 651; Belloso, 2016a, p. 168).

A menudo se materializan en la marginación institucional mediante leyes que limitan los derechos individuales, lo que conduce a la inseguridad jurídica (aplicación de la pena de muerte, tortura, tratos degradantes e inhumanos) $y$, a veces, en restricciones a la salida de ciudadanos. Por otro lado, están los geográficos (secundarios): la existencia de materias primas (conflictos abiertos o larvados, intereses trasnacionales) y catástrofes naturales (Abu-Warda, 2007, p. 40), si bien estas se identifican con la causa principal de la emigración «ambiental» (Borràs, 2006, p. 86; Gray, 2010, p.1). Finalmente, están los económicos (secundarios): crisis, nivel de desarrollo, etc., en las llamadas «migraciones económicas» (Abu-Warda, 2007, pp.37-38). 
Una vez que confluyen las causas y factores (con frecuencia múltiples), se produce el desplazamiento forzoso, inicialmente hacia Estados vecinos y después a los de asilo. La toma de decisiones estará vinculada con elementos culturales (idioma, cultura, religión) e históricos en origen (metrópoli) (Martínez y Golías, 2005, p.63), institucionales (democracias estables, desarrollo de prestaciones sociales, «efecto llamada»), pero también a la distancia (Aubarell, 2005, p. 4), frontera común y conectividad (Apostolovska et al., 2018, pp.137 y 149), a lo que se suma la presencia de "redes ilegales de tráfico". Estos elementos explican la atracción de la frontera sur de Europa (Italia, Grecia, España) aunque no necesariamente como destino final.

El peso del desarrollo económico de los Estados de la OCDE es fundamental (Hatton, 2016, p. 443) o de aquellos con políticas menos restrictivas (percibidas como «efecto llamada») o de reagrupamiento familiar. Por último, la presencia de embajadas y consulados permite que la solicitud se realice en el país de origen.

Los factores externos (colectivos) se encuentran en los países de acogida y explicarían el número y el origen de los refugiados. Se vinculan con los determinantes de la inmigración hacia los países desarrollados (Moreno y López, 2006, p.29) y es posible establecer una correlación general entre países de origen y de destino (Constantinescu, 2004, p.14).

En primer lugar, están los factores demográficos: la estructura etaria de la población (dependencia) y su composición étnica (relación entre minorías étnicas/cantidad de población extranjera y solicitantes de asilo; presencia de grupos de los países de origen) (Vink y Engelmann, 2012, pp. 550-551; Belloso, 2016b, p. 102).

En segundo lugar, se encuentran los factores socioculturales y psicosociales: religión mayoritaria (presencia de grupos fácticos) y homogeneidad social que favorecen a unos refugiados frente a otros (Ambrosini, 2016, p.16; Hofmann et al., 2019, p. 110), la conciencia y percepción de la población de acogida (Malloch y Stanley, 2005, p.55; Lueck et al., 2015, p.609), con frecuencia generada por los medios de comunicación (Ambrosini, 2016, p. 11), las redes sociales, etc. En tercer lugar, aparecen los factores económicos: períodos de crecimiento y crisis (Klepp, 2010, p.4; Belloso, 2016b, p.106), desempleo y nivel de renta (Aja et al., 2013, p.16) y políticas de gasto social (Arango et al., 2014, p.18). Por último, 
Rubén C. Lois-González, Fo Javier Garcia-Delgado Jesús Felicidades-García, María de-la-Rosa-Martínez Origen geográfico de los solicitantes de asilo y concesiones de Protección internacional

en España entre 2008 y 2018

los factores institucionales y políticos son los más abundantes a la hora de conceder la protección internacional (a menudo como «respuesta»a los factores anteriores):

- Democracia como garante de la libertad individual de los refugiados y de la aplicación del derecho de asilo/protección internacional.

- Gobiernos de derecha y de izquierda, con la aplicación de políticas restrictivas (cierre de fronteras) y disuasorias (Holzer et al., 2000, p.1.183), o solidarias (apertura, políticas de integración) (Cwener, 2004, p.76; Spehar, 2012, p.1; Lueck et al., 2015, p.609).

- Convivencia con gobiernos «aliados», firma de acuerdos de readmisión, presencia de un corpus jurídico restrictivo («ilegales») y consideración del tercer país de origen como país seguro (Rais, 2016, p.45).

- $\quad$ Política exterior comunitaria (cuotas), a menudo catalogada como inoperante por su bajo perfil político (Bačić, 2012, p.56; Montilla et al., 2017, p. 121).

- Política estatal de recepción o cierre de fronteras (Hatton y Williamson, 2006, p.250; Schuster, 2005, p.1; Goldner-Lang, 2013, p. 2; Fernández-Huertas y Rapoport, 2015, p. 2), para algunos vinculado con la cuestión de la soberanía estatal (Vink y Engelmann, 2012, p. 536).

- Electoralismo, con ingredientes de populismo/nacionalismo/neoliberalismo, estrechamente relacionado con el discurso mediático (Lueck et al., 2015, p.539), y que se ve reforzado por la presencia de partidos populistas y de extrema derecha (Kaya, 2017, p.54; Camacho, 2017, p.32; Akkerman, 2018, pp. 60-61).

En general, el miedo aparece como elemento cohesionador entre quienes deciden huir en busca de protección internacional, lo que genera un éxodo masivo, pero también contra los refugiados en la sociedad de acogida, lo que se traduce en políticas restrictivas.

Del análisis de estos factores externos es posible establecer relaciones de causalidad en la solicitud y concesión de protección internacional en España entre 2008 y 2018. 


\section{Marco metodológico}

El presente trabajo sigue la metodología planteada por García-Delgado et al. (2019) para el estudio de la evolución protección de las solicitudes y concesiones internacional en España en el período 2008-2016. Parte de fuentes estadísticas oficiales publicadas por Eurostat (2019), realizadas por los Estados firmantes del Convenio de Dublín (UE-28 más Islandia, Noruega y Suiza), que permiten hacer comparaciones y agregaciones.

En España, estas estadísticas aparecen publicadas en el informe: "El asilo en cifras", publicado anualmente por la Secretaría General Técnica del Ministerio del Interior de España, a partir de los datos recogidos por la aplicación informática «Asilo», que incorpora las variables socioeconómicas y geográficas de los peticionarios de protección internacional.

Esta fuente cuenta con información desagregada de manera diferente a Eurostat (aunque comparten datos).

Las "Directrices técnicas sobre las tablas de asilo" de Eurostat se tienen en cuenta en su elaboración, en cuanto a las variables, definiciones y desagregaciones requeridas por el Reglamento (CE) 862/2007 (MI, 2010, p. 13), pero también incluye datos correspondientes al procedimiento de apátridas, no contemplados en la citada regulación europea (MI, 2010, p. 13).

Así, las variables recopiladas a partir de las solicitudes registradas por año son: Estado de origen; desagregación por sexo; desagregación por grupo etario; lugar de presentación de las solicitudes (territorio nacional, puesto fronterizo, legación diplomática), Centro de Internamiento de Extranjeros (CIE); Comunidad Autónoma y provincia donde se formaliza la petición; datos referidos a la aplicación del Reglamento Dublín y a las solicitudes de reconocimiento del estatuto de apátrida.

El período 2008 a 2018 se aborda por la propia existencia de datos (obligatoriedad de aportarlos a Eurostat), pero también por mostrar los cambios a partir de la Ley 12/2009, de los efectos de la crisis económica internacional y de la crisis de los refugiados en un contexto de cambio de gobierno en España.

Se ha realizado una explotación estadística descriptiva de los datos de la serie disponible, atendiendo las variables de solicitudes de protección, concesiones de protección (los tres tipos) ${ }^{8}$ y origen de los solicitantes.

8 Los datos analizados solo toman en cuenta las solicitudes y concesiones de protección (las tres figuras), pero no las reclamaciones y resoluciones positivas a las mismas (en el conjunto escasas). 
Rubén C. Lois-González, Fo Javier Garcia-Delgado Jesús Felicidades-García, María de-la-Rosa-Martínez Origen geográfico de los solicitantes de asilo y concesiones de Protección internacional

en España entre 2008 y 2018

Otras variables socio-demográficas, como la provincia en la que se presentan las solicitudes, lugar físico (frontera, centro de internamiento de extranjeros, embajada etc.), nivel de formación, etc. no se toman porque los datos no son continuos en la serie estudiada.

Sin embargo, la principal limitación de la fuente es que no proporciona información sobre los motivos esgrimidos para la solicitud del estatus de refugiado de los peticionarios, por lo que no se puede realizar un análisis cualitativo, aunque sí deducir del análisis del origen (causas y factores internos). Por último, hay que tener en cuenta que gran parte de las solicitudes de protección internacional presentadas no son admitidas a trámite.

\section{Las solicitudes y las concesiones de protección internacional en España}

Durante el período 2008-2018 se registraron en España un total de 145.725 solicitudes de protección internacional. En el primer año del período hubo 4.517 solicitudes y en el último 55.749, lo que supone un crecimiento total del $1.234,20 \%$, y anualmente del $123,42 \%$. El mayor crecimiento se produce entre 2015 y 2018 , representando el $81,60 \%$ de las solicitudes del período, con diferentes comportamientos entre 2008 y 2014 (Figura 1).

Figura 1. Total de solicitudes de asilo en España, 2008-2018

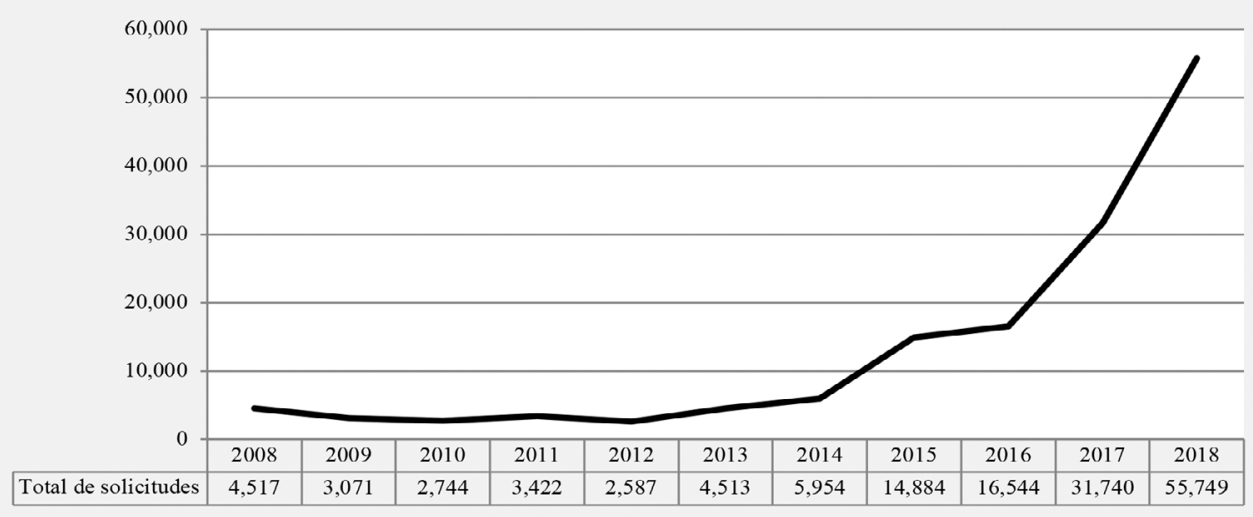

Fuente: MI, 2008 a 2018. Elaboración propia. 
En conjunto, los solicitantes en España proceden de 139 nacionalidades, además de apátridas y solicitantes de origen desconocido. El número medio de nacionalidades de los solicitantes es de 101 al año, con tendencia a aumentar desde 2015 (Figura 2).

Un total de 67 nacionalidades aparecen cada año en la serie como solicitantes. Entre el total de solicitantes, hay un grupo de nacionalidades que siempre es rechazado (aunque es marginal en el total): UE-28 (44 solicitudes de 12 Estados) y de otros considerados seguros (Estados OCDE).

Figura 2. Total de nacionalidades de las solicitantes de asilo en España, 2008-2018

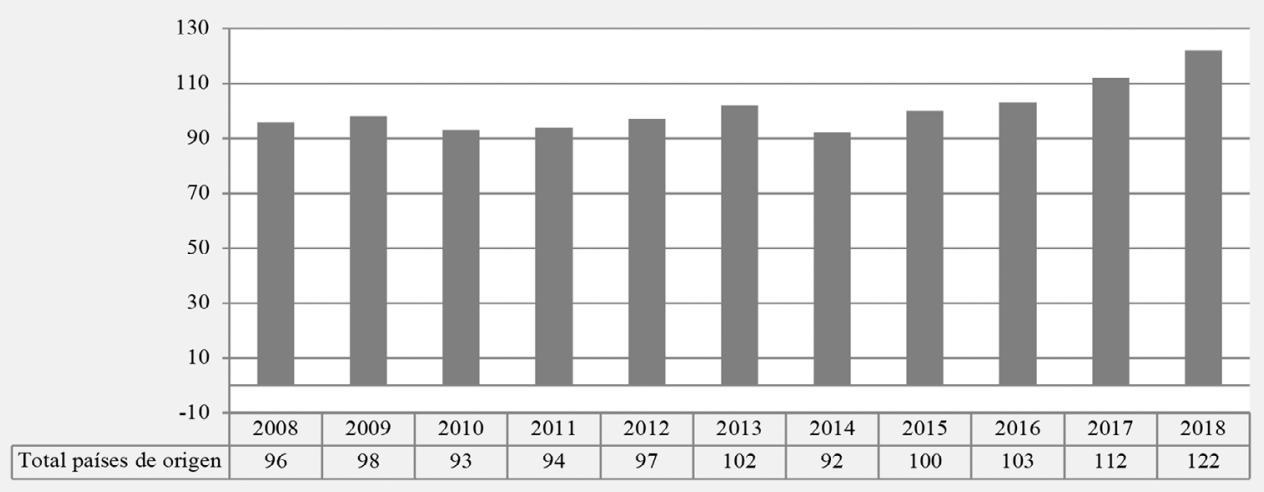

Fuente: MI, 2008 a 2018. Elaboración propia

El 97,17\% de los solicitantes de protección internacional en España fueron de 51 nacionalidades ( $>0,15 \%$ del total) (Figura 3). Las diez primeras suponen el $72,87 \%$ de las solicitudes del período: venezolana (24,57\% del total del período), siria (12,95\%), colombiana $(9,31 \%)$, ucraniana $(7,94 \%)$, argelina $(3,76 \%)$, palestina $(3,54 \%)$, hondureña $(2,92 \%)$, salvadoreña $(2,90 \%)$, maliense $(2,58 \%)$ y nigeriana $(2,41 \%)$.

El primer puesto de las solicitudes ha estado encabezado 3 anualidades por venezolanos (2016, 2017 y 2018) y sirios (2012, 2014 y 2015), 2 por nigerianos (2008 y 2009) y 1 por malienses (2013), cubanos (2010) y costamarfileños (2011), estos dos últimos no figuran entre 10 primeros puestos. 
Rubén C. Lois-González, Fo Javier Garcia-Delgado Jesús Felicidades-García, María de-la-Rosa-Martínez Origen geográfico de los solicitantes de asilo y concesiones de Protección internacional

en España entre 2008 y 2018

Figura 3. Total de solicitudes de protección internacional en España por nacionalidad del solicitante, acumulado 2008-2018

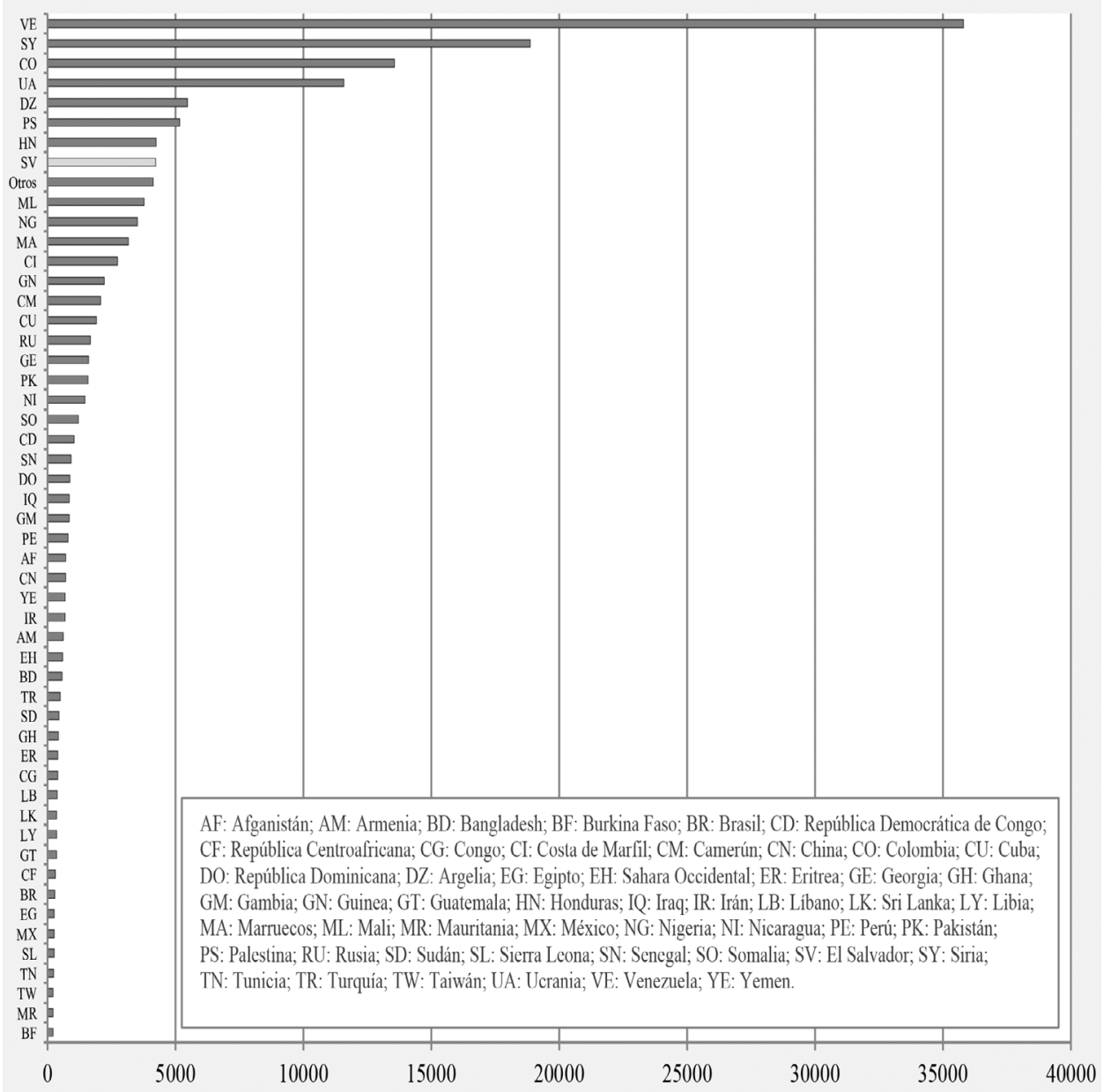

Fuente: MI, 2008 a 2018. Elaboración propia

Las tendencias del período pueden establecerse sobre la base de la evolución de las solicitudes de protección internacional por nacionalidad (Figura 4). Las solicitudes de los ciudadanos venezolanos, que no estuvieron entre los 10 primeros hasta 2014, aumentaron exponencialmente entre 2016 y 2018 (3.264,60\% en 2018 sobre 2015) para ocupar el primer lugar esos tres años. 
Las solicitudes de ciudadanos sirios conocen un retroceso en 2009 y 2010, situándose a la cabeza del ranking en 2014 y 2015, con un descenso gradual desde ese año. La tercera nacionalidad es la colombiana, que también se disparó a partir de 2016 (un aumento de 6.835,66\% en 2018 sobre 2015), tras haber estado fuera de los 10 primeros puestos entre 2012 y 2015. El número de solicitudes de ucranianos es relevante a partir de 2014 con un máximo en 2015, para disminuir constantemente en el resto de anualidades.

La quinta nacionalidad más numerosa es la argelina, la única presente entre las 10 primeras todo el período, se mantiene constante hasta 2013, año en el que las solicitudes aumentaron un 75,25\% con respecto al año anterior, disminuyendo ligeramente en 2014 para duplicarse en 2015 y conocer un nuevo incremento a partir de 2016.

Los solicitantes de protección palestinos aparecen a partir de 2010, con altibajos, creciendo exponencialmente en 2015, 2017 y 2018. El séptimo y octavo puestos son ocupados por hondureños y salvadoreños, que experimentan un importante crecimiento desde 2016, y desplazan a ciudadanos cubanos y costamarfileños por número de solicitudes en 2017 y 2018. Los malienses son la novena nacionalidad y figuran entre las 10 primeras solicitantes entre 2012 y 2015, con un máximo en 2013 ( $1^{\mathrm{a}}$ nacionalidad).

Por último, los nigerianos experimentan altibajos a lo largo del período, pasando de ser la primera nacionalidad en 2008 a salir de las 10 primeras nacionalidades en 2017.

Respecto al reconocimiento de protección entre 2008 y 2018 en España se han estimado en primera instancia 5.753 solicitudes de asilo, lo que representa el 2,45\% de las mismas. En el mismo período, se concede protección subsidiaria a 16.992 solicitantes, el 16,11\% del total. Por último, solo 188 solicitantes han recibido autorizaciones de estancia o residencia por razones humanitarias $(0,12 \%)$. No recibieron protección alguna 121.402 solicitantes, es decir, el 83,31\%. 
Rubén C. Lois-González, $F^{c o}$ Javier Garcia-Delgado Jesús Felicidades-García, María de-la-Rosa-Martínez Origen geográfico de los solicitantes de asilo y concesiones de Protección internacional

en España entre 2008 y 2018

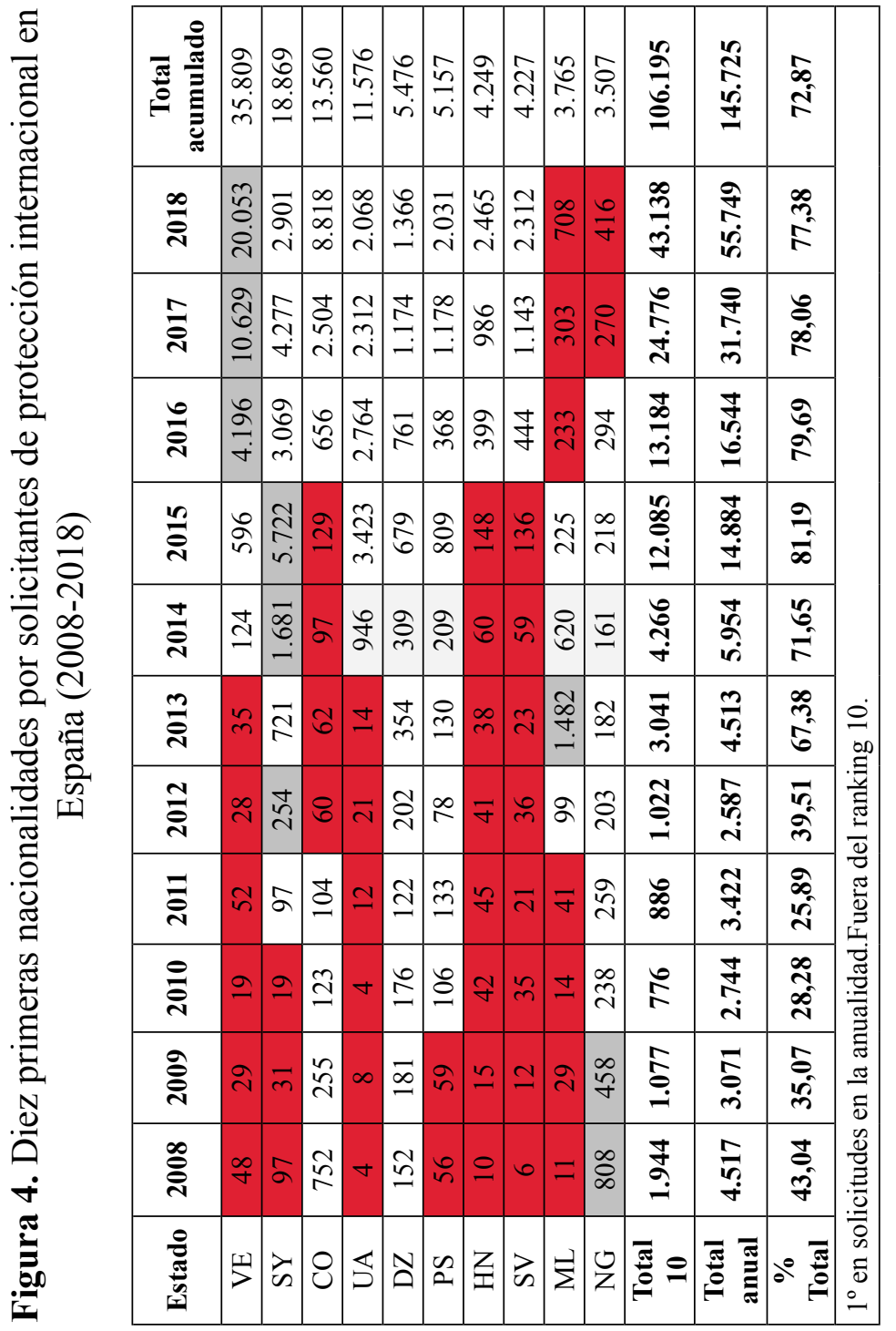

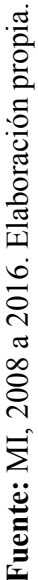


Rubén C. Lois-González, F $F^{c o}$ Javier Garcia-Delgado Jesús Felicidades-García, María de-la-Rosa-Martínez Geographical origin of asylum seekers and international protection concessions in Spain between 2008 and 2018

Figura 5. Reconocimiento de la condición de refugiado, del derecho a la protección subsidiaria y autorizaciones de estancia o residencia por razones humanitarias en España (2008-2018)

\begin{tabular}{|c|c|c|c|c|c|}
\hline Figura de protección & Variable & 2008 & 2009 & 2010 & 2011 \\
\hline \multirow{2}{*}{ Derecho de asilo } & $\mathrm{N}^{\mathrm{o}}$ & 150 & 179 & 255 & 337 \\
\hline & $\%$ solicitudes & 3,32 & 5,83 & 9,29 & 9,85 \\
\hline \multirow{2}{*}{ Protección subsidiaria } & $\mathrm{N}^{\mathrm{o}}$ & 10 & 162 & 350 & 630 \\
\hline & $\%$ solicitudes & 0,22 & 5,28 & 12,76 & 18,41 \\
\hline \multirow{2}{*}{ Razones humanitarias } & $\mathrm{N}^{\mathrm{o}}$ & 126 & 8 & 15 & 21 \\
\hline & $\%$ solicitudes & 2,79 & 0,26 & 0,55 & 0,61 \\
\hline Figura de protección & Variable & 2012 & 2013 & 2014 & 2015 \\
\hline \multirow{2}{*}{ Derecho de asilo } & $\mathrm{N}^{\mathrm{o}}$ & 232 & 203 & 384 & 218 \\
\hline & $\%$ solicitudes & 8,97 & 4,50 & 6,45 & 1,46 \\
\hline \multirow{2}{*}{ Protección subsidiaria } & $\mathrm{N}^{\mathrm{o}}$ & 320 & 287 & 1.199 & 802 \\
\hline & $\%$ solicitudes & 12,37 & 6,36 & 20,14 & 5,39 \\
\hline \multirow{2}{*}{ Razones humanitarias } & $\mathrm{N}^{\mathrm{o}}$ & 12 & 4 & 2 & 0 \\
\hline & $\%$ solicitudes & 0,46 & 0,09 & 0,03 & 0 \\
\hline Figura de protección & Variable & 2016 & 2017 & 2018 & $\begin{array}{c}\Sigma / \mu \\
(2008-2018) \\
\end{array}$ \\
\hline \multirow{2}{*}{ Derecho de asilo } & $\mathrm{N}^{\mathrm{o}}$ & 369 & 626 & 620 & 3.573 \\
\hline & $\%$ solicitudes & 2,33 & 2,53 & 1,44 & 5,09 \\
\hline \multirow{2}{*}{ Protección subsidiaria } & $\mathrm{N}^{\mathrm{o}}$ & 6.482 & 4.192 & 2.558 & 16.992 \\
\hline & $\%$ solicitudes & 39,18 & 16,92 & 5,93 & 13,00 \\
\hline \multirow{2}{*}{ Razones humanitarias } & $\mathrm{N}^{\mathrm{o}}$ & 0 & 0 & 0 & 188 \\
\hline & $\%$ solicitudes & 0 & 0 & 0 & 0,44 \\
\hline
\end{tabular}

Fuente: MI, 2008 a 2018. Elaboración propia.

La media anual del período de reconocimiento de la condición de refugiado es del 5,09\% de las solicitudes presentadas (Figura 5). Porcentualmente, es entre 2010 y 2012 cuando más se conceden, pero en números absolutos son los años 2017 y 2018.

El número medio anual de concesiones de protección subsidiaria es del $13 \%$ del total de solicitudes, con un comportamiento muy variable de la serie. Aumenta de 2008 a 2011, conociendo este último año un crecimiento interanual del 80,57\%, para caer en $2012(-31,16 \%)$ y $2103(-10,31 \%)$. De nuevo, en 2014, se dispara (crecimiento interanual de 317,78\%) para caer en 2015 (-3,11\%), volver a dispararse en 2016 (708,23\% de crecimiento interanual) y finalmente descender en 2017 (-35,33\%) y 2018 (-38,98\%). 
Rubén C. Lois-González, Fo Javier Garcia-Delgado Jesús Felicidades-García, María de-la-Rosa-Martínez Origen geográfico de los solicitantes de asilo y concesiones de Protección internacional

en España entre 2008 y 2018

Por último, las autorizaciones de estancia o residencia por razones humanitarias fueron solo 188 ( $0,44 \%$ de media anual), de las cuales 126 $(67,02 \%)$ se concedieron en 2008 , cuando representaron el $2,79 \%$ de las solicitudes de protección internacional presentadas, cifra que disminuye a partir de ese año hasta su desaparición en 2015.

A pesar de la diversidad de nacionalidades de los solicitantes en España, el número que recibe el estatus de refugiados es reducido, oscilando entre 24 en 2008 y 48 en 2017, con un total de 79 (56,83\% de nacionalidades solicitantes), incluidos taiwaneses, saharauis, tibetanos y palestinos, además de apátridas y de origen desconocido (Figura 6).

El 97,45\% de las concesiones de asilo durante el período se corresponden con 52 nacionalidades, apátridas o de origen desconocido. La protección subsidiaria se otorgó a personas de 49 nacionalidades $(35,25 \%$ del total), además de las de origen desconocido. Por su parte, la protección por razones humanitaria se concedió a personas de 37 nacionalidades $(26,62 \%)$, aparte de los de origen desconocido y apátridas. En total, 87 nacionalidades $(62,59 \%$ del total), además de apátridas y de origen desconocido, recibieron algún tipo de protección.

En cuanto a la concentración de concesiones del derecho de asilo, diez nacionalidades representan el 66,58\% del total (Figura 7). Los palestinos son el grupo de refugiados más numeroso (las concesiones se dispararon en 2017), seguidos por pakistaníes (constantes durante todo el período), sirios (concentrados en los últimos años, especialmente en 2014), eritreos (con un incremento exponencial en 2017), colombianos (con tendencia a la baja desde 2011, pero se disparan en 2018), marroquíes (con un aumento notable en 2017 y 2018), rusos y afganos (con altibajos), ucranianos (solo presentes desde 2016, las concesiones se disparan en 2018) y cubanos (con un cénit en 2011, y a partir de ese año son escasas). Solo pakistaníes, colombianos, rusos y afganos aparecen en todas las anualidades, seguidos por cubanos (10 años) y palestinos, sirios y eritreos ( 9 años).

Las concesiones de protección subsidiaria muestran un cambio con respecto a las otras figuras en las diez principales nacionalidades (sirios, cubanos, somalíes, ucranianos, palestinos, iraquíes, afganos, costamarfileños, ceilandeses y yemeníes), que en conjunto representan el 97,70\% del total del período. Solo dos nacionalidades están presentes en los 11 años de la serie (cubana y costamarfileña), en 10 la somalí y afgana, palestina en 9 
Figura 6. Reconocimiento de la condición de refugiado, del derecho a la protección subsidiaria y autorizaciones de estancia o residencia por razones humanitarias en España por Estado/territorio (2008-2018). Números absolutos

\begin{tabular}{|c|c|c|c|c|c|c|c|c|c|}
\hline Estado & $\begin{array}{l}\text { Derecho } \\
\text { de asilo }\end{array}$ & $\begin{array}{l}\text { Protección } \\
\text { subsidiaria }\end{array}$ & $\begin{array}{c}\text { Razones } \\
\text { humani- } \\
\text { tarias }\end{array}$ & Total & Estado & $\begin{array}{l}\text { Dere- } \\
\text { cho de } \\
\text { asilo }\end{array}$ & $\begin{array}{l}\text { Protec- } \\
\text { ción sub- } \\
\text { sidiaria }\end{array}$ & $\begin{array}{c}\text { Razones } \\
\text { humani- } \\
\text { tarias }\end{array}$ & Total \\
\hline SY & 268 & 13.513 & 1 & 13.782 & ML & 13 & 26 & 0 & 39 \\
\hline PS & 629 & 411 & 2 & 1.042 & GQ & 20 & 3 & 13 & 36 \\
\hline $\mathrm{CU}$ & 107 & 792 & 5 & 904 & LB & 16 & 10 & 1 & 27 \\
\hline $\mathrm{SO}$ & 38 & 642 & 8 & 688 & $\mathrm{AM}$ & 25 & 0 & 0 & 25 \\
\hline UA & 116 & 446 & 1 & 563 & HT & 15 & 0 & 9 & 24 \\
\hline PK & 369 & 24 & 1 & 394 & LY & 13 & 11 & 0 & 24 \\
\hline IQ & 99 & 236 & 54 & 389 & TR & 23 & 1 & 0 & 24 \\
\hline $\mathrm{AF}$ & 138 & 222 & 6 & 366 & AP & 15 & 0 & 8 & 23 \\
\hline ER & 233 & 30 & 0 & 263 & $\mathrm{CN}$ & 21 & 2 & 0 & 23 \\
\hline $\mathrm{CO}$ & 188 & 32 & 8 & 228 & $\mathrm{JO}$ & 17 & 5 & 1 & 23 \\
\hline $\mathrm{CI}$ & 17 & 181 & 8 & 206 & $\mathrm{MX}$ & 21 & 0 & 1 & 22 \\
\hline MA & 166 & 6 & 8 & 180 & $\mathrm{BD}$ & 14 & 7 & 0 & 21 \\
\hline RU & 165 & 5 & 4 & 174 & $\mathrm{BY}$ & 19 & 0 & 0 & 19 \\
\hline LK & 24 & 82 & 2 & 108 & EH & 17 & 1 & 0 & 18 \\
\hline YE & 26 & 77 & 0 & 103 & GM & 16 & 0 & 1 & 17 \\
\hline IR & 86 & 7 & 2 & 95 & EG & 16 & 0 & 0 & 16 \\
\hline VE & 72 & 0 & 2 & 74 & GT & 8 & 7 & 0 & 15 \\
\hline $\mathrm{CD}$ & 47 & 21 & 3 & 71 & $\mathrm{TG}$ & 14 & 1 & 0 & 15 \\
\hline $\mathrm{CM}$ & 63 & 2 & 2 & 67 & $\mathrm{UZ}$ & 15 & 0 & 0 & 15 \\
\hline DS & 54 & 8 & 1 & 63 & NI & 12 & 2 & 0 & 14 \\
\hline ET & 10 & 49 & 2 & 61 & $\mathrm{SL}$ & 8 & 3 & 3 & 14 \\
\hline NG & 49 & 3 & 9 & 61 & GN & 11 & 1 & 1 & 13 \\
\hline SD & 15 & 42 & 0 & 57 & $\mathrm{AO}$ & 2 & 3 & 6 & 11 \\
\hline $\mathrm{DZ}$ & 43 & 9 & 4 & 56 & $\mathrm{GE}$ & 8 & 3 & 0 & 11 \\
\hline $\mathrm{CF}$ & 1 & 55 & 0 & 56 & $\mathrm{KZ}$ & 10 & 0 & 0 & 10 \\
\hline $\mathrm{HN}$ & 45 & 0 & 0 & 45 & Otros & 91 & 10 & 8 & 109 \\
\hline $\mathrm{AZ}$ & 42 & 1 & & 43 & \multicolumn{5}{|c|}{$\begin{array}{l}\text { AO: Angola; AP: apátridas; AZ: Azerbaiyán; BY: } \\
\text { Bielorrusia; DS: origen desconocido; ET: Etiopía; } \\
\text { GQ: Guinea Ecuatorial;HT: Haití; JO: Jordania; } \\
\text { KZ: Kazajistán; TG: Togo; UZ: Uzbekistán. }\end{array}$} \\
\hline
\end{tabular}

Fuente: MI, 2008 a 2018. Elaboración propia. 
Rubén C. Lois-González, Fo Javier Garcia-Delgado Jesús Felicidades-García, María de-la-Rosa-Martínez Origen geográfico de los solicitantes de asilo y concesiones de Protección internacional

en España entre 2008 y 2018

y ceilandesa en 8 , mientras que los ucranianos y yemeníes solo aparecen en 4 y 3 años de la serie, respectivamente, al final de ésta.

Por último, las autorizaciones de estancia o residencia por razones humanitarias solo destacan en los casos iraquíes y ecuatoguineano, aunque las nacionalidades más frecuentes son la nigeriana (cinco anualidades), haitiana y marroquí (cuatro).

Figura 7. Reconocimiento de protección internacional en España por procedencia (2008-2018). Porcentajes

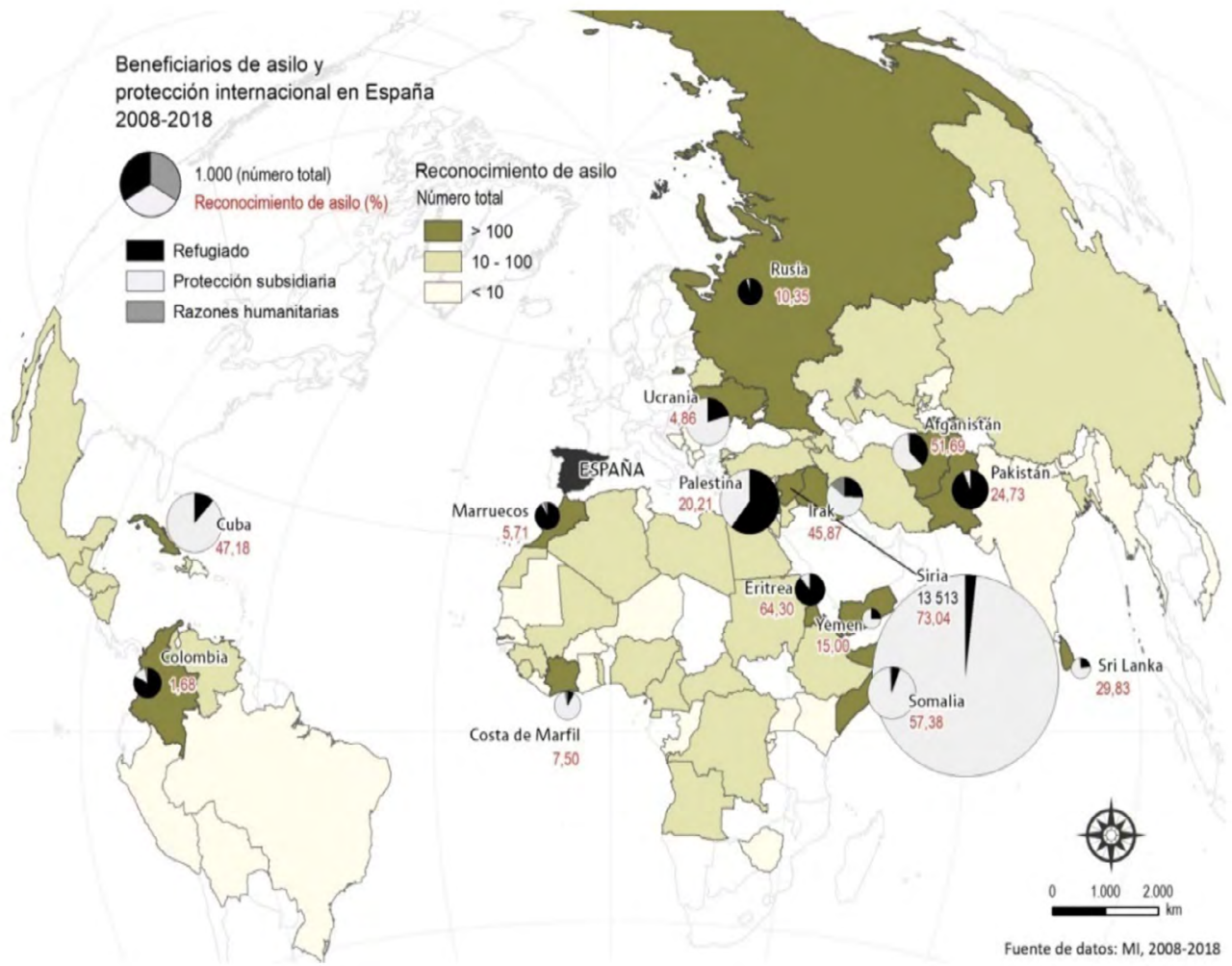

Fuente: MI, 2008-2018.

Durante el siglo XX, España fue un país «productor de refugiados» (Valles, 2016, p. 228) y de emigración, para convertirse recientemente en un país de inmigración (Galeote, 2009, p. 54). Esto, unido a la larga dictadura franquista, motivó que el derecho de asilo no fuese regulado hasta la 
Ley 5/1984, tras la ratificación, el 22 de julio de 1978, de la Convención de Ginebra y el Protocolo de Nueva York (Galeote, 2009, pp.54-55).

Los resultados permiten analizar los cambios que se han producido en España entre 2008 y 2018 en las solicitudes y concesión de protección internacional, teniendo en cuenta la nacionalidad de los solicitantes y beneficiarios de protección.

Durante este período, la evolución de las solicitudes y concesiones de protección internacional es desigual. Las solicitudes se redujeron en tres años de la serie $(2009,2010$ y 2012), mientras que las concesiones de asilo y protección subsidiaria aumentaron en cinco (2009, 2010, 2011, 2014 y 2016).

En 2017, solo aumentaron las concesiones de asilo, que cayeron en 2018, mientras que las concesiones de protección subsidiaria también disminuyeron en 2017 y 2018. Por último, las autorizaciones por razones humanitarias solo aumentaron en 2010 y 2011, hasta desaparecer completamente en 2015.

Esta lectura es importante porque el inicio de la serie coincide con un cambio normativo (Ley 12/2009). Concretamente, durante 2009 y 2010, el asilo apenas aumentó en comparación con la protección subsidiaria, en un contexto en el que las solicitudes retrocedieron como consecuencia de la crisis económica. A partir de 2011, tanto las solicitudes como las concesiones de protección aumentaron tras «la primavera árabe» del Norte de África y Oriente Próximo.

En 2012 y 2013 habrá un aumento de las solicitudes de protección y un retroceso de concesiones de protección internacional, especialmente por razones humanitarias. A partir de 2014, la «crisis de los refugiados» convierte a 2015 en el «año de los refugiados» (Arango et al., 2016, p.25), cuando las solicitudes se acercaron a los niveles comunitarios.

En 2016, las solicitudes y concesiones de protección subsidiaria se dispararon; en 2017 y 2018 las solicitudes aumentaron (el mayor crecimiento del período), incrementándose también las concesiones de asilo (casi el doble en 2017, permaneciendo a la baja en 2018), mientras que las concesiones de protección subsidiaria retrocedieron en estos dos años.

En el análisis por nacionalidad, los datos indican una reiteración de las solicitudes, que está relacionada con las causas de solicitud de protección internacional y, desde 2015, con la presencia de cuotas comunitarias. 
Rubén C. Lois-González, Fo Javier Garcia-Delgado Jesús Felicidades-García, María de-la-Rosa-Martínez Origen geográfico de los solicitantes de asilo y concesiones de Protección internacional

en España entre 2008 y 2018

En total, los solicitantes de 79 nacionalidades, además de apátridas y de origen desconocido, reciben protección internacional. Solo pakistaníes, colombianos, rusos, afganos e iraníes reciben asilo cada año de la serie, mientras que únicamente cubanos y costamarfileños reciben protección subsidiaria durante 11 años, sin reiteraciones en el caso de las autorizaciones por razones humanitarias.

En su conjunto, entre 2008 y 2016 predominan los solicitantes de países africanos $(22,36 \%)$ y asiáticos $(21,99 \%)$, lo que demuestra un cambio frente a un proceso de latinización de la inmigración desde finales de los años noventa (Martínez y Golías, 2005, p. 51).

Sin embargo, en el último bienio, el número de solicitudes de colombianos y venezolanos, se ha disparado, situando a América a la cabeza $(44,37 \%)$ del período, pero es necesario ver cómo evoluciona para establecer la tendencia, ya que los europeos suponen el 11,07\% de las solicitudes.

Esto contrasta con la nacionalidad de las personas que reciben protección internacional. Así, las nacionalidades asiáticas representan el 55,15\% del asilo y el $85,92 \%$ de la protección subsidiaria, frente a las africanas, con el $23,85 \%$ y el $6,42 \%$ respectivamente, las americanas, con el $13,52 \%$ y el $4,93 \%$, y las europeas con el 7,47\% de los refugiados y el $2,68 \%$ de la protección subsidiaria.

Solo las autorizaciones por razones humanitarias están dominadas por nacionalidades africanas $(39,89 \%)$, aunque las asiáticas están muy cerca $(38,30 \%)$. En resumen, las concesiones de protección internacional (las tres figuras) de africanos suponen el 6,01\% del total de sus solicitudes, las de asiáticos registran el 51,46\%, las europeas el 4,48\% y las de americanos caen hasta el $2,06 \%$.

De la interpretación de estos datos se deduce una preferencia por los solicitantes americanos y la aplicación de cuotas a los asiáticos por encima del contingente africano (considerado emigrante económico) y de los europeos (consideración de países seguros), ya que "las sociedades receptoras seleccionan los inmigrantes que reciben, acogen una parte sin demasiados problemas e intentan rechazar a otras" (Ambrosini, 2016, p. $3,16)$. Desde esta perspectiva, como señala Borja (2017, p. 31), puede hablarse de "refugiados de primera y de segunda categoría" al primar a unos grupos sobre otros. 
Los solicitantes de protección internacional en España se concentran en una decena de nacionalidades, cada una de ellas sufre cambios en el proceso, pero es posible establecer las causas de la solicitud (temor a ser perseguido por causas individuales/personales) y los factores internos (y su incremento o retroceso). Por otra parte, la escasez de solicitantes libios, egipcios y tunecinos llama la atención, lo que indica preferencias hacia la metrópoli, razones culturales y de localización.

En cuanto a la toma de decisiones (Cebrián, 2009, p. 49), los flujos migratorios y la solicitud de protección internacional en España se definen por su condición de frontera Sur de la UE, siendo el único país europeo con frontera terrestre en África, lo que le confiere la condición de acceso de la ruta migratoria del Mediterráneo Occidental (Aubarell, 2005, p. 2).

El efecto frontera atrae a africanos, especialmente a argelinos (presentes desde los años ochenta), nigerianos, malienses y de otras nacionalidades (costamarfileños, marroquíes), ya que España se concibe como un destino de tránsito y etapa del proyecto vital con destino final en países como Alemania o Suecia (Ambrosini, 2016, p. 5).

Hay que tener en cuenta que los países del sur de Europa han fomentado tradicionalmente el paso hacia el norte sin comprometer la seguridad interior (Ambrosini, 2014, pp.236-237). En parte, esto justifica que no se presenten solicitudes de protección, porque estas personas realmente intentar llegar a otros espacios europeos (Manzanedo y Forina, 2016, p. 232).

Por su parte, venezolanos, colombianos, hondureños, salvadoreños y cubanos dominan los vínculos culturales (idioma, historia común) y la conectividad (acceso aéreo), haciendo de España su destino final.

\section{Causas de las peticiones de protección internacional}

Es difícil determinar las causas de las solicitudes de protección internacional (Morgades, 2014, p. 230), aunque en algunos estudios se indican por país (CEAR, 2018). El principal factor interno que conduce a la solicitud, y que multiplica el número de nacionalidades demandantes, es la existencia de un contexto de violencia en el territorio de origen (conflicto armado o estado de guerra), en el que surgen nuevos escenarios de conflicto (Gabanes, 2014, p. 205). Estas condiciones se identifican en cinco de las principales nacionalidades solicitantes; de hecho, explican su evolución. 
Rubén C. Lois-González, Fo Javier Garcia-Delgado Jesús Felicidades-García, María de-la-Rosa-Martínez Origen geográfico de los solicitantes de asilo y concesiones de Protección internacional

en España entre 2008 y 2018

En Colombia, el origen se sitúa en el conflicto armado interno (guerrillas, paramilitares) y el narcotráfico, donde el factor económico interviene en la demanda de protección, con una disminución durante la crisis económica (retornados desde España) y un aumento con la recuperación (desde 2012).

El aumento de solicitudes, a pesar de los acuerdos de paz del presidente Santos, se puede explicar por el clima de inseguridad y extorsión, pero también por la eliminación de la obligatoriedad de visado en la UE (19/12/2015) (CEAR, 2018, p. 55), lo que evidencia el trasfondo económico de las solicitudes.

También hay un aumento del número de solicitantes en países con problemas con grupos armados islamistas (Díez, 2015, p. 4). Es el caso de Nigeria con Boko Haram, que crea un territorio propio en 2015 que afecta también a Mali, Níger, Camerún y Chad.

En la República Democrática de Congo, la acción de las guerrillas, los grupos rebeldes y las luchas por los recursos son algunas de las razones de las solicitudes, al principio y al final del período. El conflicto israelípalestino ha provocado altibajos en las peticiones a lo largo del período, coincidiendo con la diáspora palestina desde Siria9

En Costa de Marfil, tras el fin de la guerra civil, la inestabilidad interna motivó la demanda de asilo de sus nacionales hasta 2011, que descendió a partir de ese año, a pesar de los problemas a los que se enfrentan los retornados (Gabanes, 2014, p. 205).

En Mali se dan situaciones de guerra abierta, cuyos nacionales figuran entre los diez primeros demandantes de protección a partir de 2012, coincidiendo con la rebelión tuareg y la aparición de grupos islamistas radicales, la declaración de independencia de las provincias del norte, el golpe de Estado y el cierre de las fronteras, además de la intervención francesa a partir de 2013.La guerra en Ucrania desde 2014 desencadena solicitudes de protección a España, donde ya reside una importante comunidad ucraniana.

En este caso, el reagrupamiento familiar (factor externo) coincide con el flujo de principios del siglo XXI (González y Aguilera, 2000, p. 258) y con las situaciones no solucionadas en el espacio postsoviético.

9 Descienden en 2016 por la dificultad de acceder a la oficina de asilo de Melilla (CEAR, 2018, p. 56). 
Finalmente, el conflicto de Siria es el que ha generado una mayor demanda de protección internacional, siendo el principal factor entre 2012 y 2015.

La inseguridad individual, también presente en los países mencionados, es el segundo factor interno que motiva la petición de protección internacional. En el caso de Venezuela, ha habido un incremento significativo desde 2013, hasta convertirse en el principal país solicitante desde 2016. También afecta a países de Centroamérica, como El Salvador y Honduras, con altos índices de criminalidad (grupos de delincuencia organizada), pobreza y desempleo, y que desde 2015 inician un redireccionamiento hacia Europa (Arango et al., 2017, p. 13) coincidiendo con la recuperación económica, que se incrementará con las políticas antiinmigración de Trump.

La falta de libertades individuales (dictaduras, autocracias) es importante como factor interno que conduce a la solicitud de asilo. Vinculado a la inestabilidad interna, aparece en los países de la «Primavera Árabe» (desde octubre de 2010) y la represión posterior (Andreatta, 2017 , p. 3). Afecta a Argelia y Siria (antes de la guerra abierta) y se aprecia entre los marroquíes y saharauis (2011). No es exclusivo del mundo árabe, y estaría detrás de las solicitudes de ucranianos antes de la caída de Yanukovich (2014).

En los países con inestabilidad interna o con falta de libertades individuales, se da con frecuencia la marginación de grupos sociales. Este es el caso de China, con la represión de disidentes y minorías étnicas (20132015), lo que se traduce en un aumento de las solicitudes de asilo (2015).

La limitación por ley de derechos individuales es común en países musulmanes, como la discriminación contra las mujeres o contra la homosexualidad. Aunque no es posible rastrear este factor interno a través de la fuente de datos, cabe señalar que de los 19 países que aparecen entre los diez primeros solicitantes en el período, dos de ellos (Pakistán e Irak) aplican la pena de muerte a los homosexuales, y en siete casos son condenados a prisión (Siria, Argelia, Nigeria, Marruecos, Somalia, Guinea y Camerún), mientras que en El Salvador y Honduras son claramente discriminados (ILGA, 2019).

La crisis económica generalizada en muchos de estos países acompaña los factores anteriores (Moreno y López, 2006, p. 24), siendo Venezuela un claro ejemplo. Teniendo en cuenta el IDH de 2016 (PNUD, 2017), el nivel de desarrollo de 7 de los 19 países analizados es bajo (mínimo en 
Rubén C. Lois-González, Fo Javier Garcia-Delgado Jesús Felicidades-García, María de-la-Rosa-Martínez Origen geográfico de los solicitantes de asilo y concesiones de Protección internacional

en España entre 2008 y 2018

Guinea, que ocupa el puesto $183^{\circ}$ mundial de 188 , con 0,414$)$, mientras que el resto está por debajo del 0,775 de Cuba (puesto $68^{\circ}$ ). Este elemento genera emigración y es fuente de solicitudes de protección internacional, aunque no sea causa para otorgarla.

Por otro lado, la concesión de protección internacional en España por nacionalidades contrasta con las solicitudes. El estatus de refugiado se concede a 79 nacionalidades, de las cuales las diez primeras acumulan el 66,58\%, siendo (por orden de importancia): palestina, paquistaní, siria, eritrea, colombiana, marroquí, rusa, afgana, ucraniana y cubana.

De éstas, solo cuatro (palestina, siria, colombiana, y ucraniana) aparecen entre las diez con más solicitantes. En consecuencia, no existe una relación directa entre el número de solicitudes y el de concesiones de asilo, ya que muchas se rechazan sistemáticamente (malienses, nigerianos, costamarfileños, venezolanos, argelinos), en principio por causas objetivas (no cumplen los requisitos estipulados).

La concesión de protección subsidiaria se reduce a 50 nacionalidades (y personas de origen desconocido). Las diez primeras suponen un $97,70 \%$ del total, con una concentración de sirios (79,53\%), seguidos de cubanos, somalíes, ucranianos, palestinos, iraquíes, afganos, costamarfileños y, a distancia, ceilandeses y yemeníes.

Los mayores solicitantes (colombianos, argelinos, salvadoreños, malienses y nigerianos) no aparecen entre quienes más la reciben. Incluso, este tipo de protección no se concede a venezolanos, malienses y hondureños. Solo en el caso de la población siria existe una clara correlación entre el número de solicitudes y la protección subsidiaria, siendo marginal entre el resto de las nacionalidades, especialmente las africanas (excepto los costamarfileños).

Finalmente, la autorización de permanencia o residencia por razones humanitarias se concede a 37 nacionalidades, apátridas y personas de origen desconocido. Las diez primeras son iraquí, ecuatoguineana, nigeriana, colombiana, marroquí, somalí, costamarfileña y apátridas. No existe ninguna correlación entre las solicitudes y las concesiones, mientras que el bajo nivel de concesiones y su excepcionalidad solo la hace importante entre los iraquíes. Se detecta que se utiliza excepcionalmente en catástrofes naturales (terremoto de Haití de 2010) y no se aplica en caso de conflicto en el país de origen. La lectura de datos permite afirmar que en tiempos 
de crisis no existen razones humanitarias de asilo, y que éstas desaparecen cuando aumenta el número de solicitudes.

En general, hay una tendencia a acumular concesiones en determinadas nacionalidades, mientras que $58(1,13 \% \text { de las solicitudes })^{10}$ no reciben ningún tipo de protección (entre chadianos, ghaneses y nigerinos o argentinos y paraguayos).

La correlación de las tres figuras por nacionalidad muestra también una tendencia a concederlas a los que tienen más solicitantes, pero también un retroceso progresivo del uso del derecho de asilo en favor de la protección subsidiaria (es el caso de los sirios y los cubanos), excepto en el último bienio.

\section{Discusión}

Las concesiones de protección internacional, a pesar de ser una condición individual, pueden estudiarse por nacionalidad para determinar los factores externos que explican el funcionamiento de la política de asilo en España.

En comparación con el resto de la UE, el porcentaje de solicitudes de protección internacional en España es bajo (Valles, 2016, p. 228; Morgades, 2014, p. 230), mientras que el de inadmisión es muy superior al de otros países (Morgades, 2014, p. 232; Mangas, 2016, p.6-7). Por tanto, no es una cuestión cuantitativa si se tiene en cuenta el porcentaje de protecciones otorgadas sobre la población española $(<0,09 \%$ en 2018$)$ o sobre el total de residentes de otras nacionalidades $(0,88 \%)$ (INE, 2019), porque como señalan Padilla y Golberg (2017, p. 24), la «crisis de los refugiados» se encuentra entre lo simbólico (perceptual) y lo real.

Los factores demográficos y socioculturales están relacionados con la percepción que tiene la población del fenómeno estudiado. Básicamente, aunque exista una gran causalidad, aparece la noción de otredad de los refugiados (Gabanes, 2014, p. 199), manifestada en el miedo al diferente.

La confusión entre inmigrante y refugiado subyace en la importancia que se da al fenómeno del asilo, sin tener en cuenta que "no sufren lo mismo, no tienen la misma situación extrema” (Mangas, 2016, p. 5). A ello se añade la existencia de un límite difuso entre el refugio y otras causas

10 Doce de ellas son comunitarias, lo que provoca su desestimación de oficio. 
Rubén C. Lois-González, Fo Javier Garcia-Delgado Jesús Felicidades-García, María de-la-Rosa-Martínez Origen geográfico de los solicitantes de asilo y concesiones de Protección internacional

en España entre 2008 y 2018

(Triandafyllidou y Mantanika, 2017, p. 9) (concepto de migraciones mixtas), como las socioeconómicas y de asilo (Abu-Warda, 2007, p. 39; Prieto, 2013, p. 104; Ambrosini, 2016, p. 4; Belloso, 2016b, p. 141).

En algunos casos, la importancia de las redes sociales de inmigración (Constantinescu, 2004, p. 12) determina el incremento de solicitudes (Mallett y Hagen-Zanker, 2016, p. 57), como entre los colombianos (4,10\% de los residentes extranjeros), venezolanos (2,74\%), y ucranianos $(2,22 \%)$, que representan el tercer, cuarto y sexto grupo de población extracomunitaria en España (INE, 2019). Esto interviene en el proceso de toma de decisiones para solicitar protección internacional, pero no se detecta su influencia sobre las concesiones; por el contrario, actúa para evitar el efecto llamada.

La cultura cristiana y la percepción de la población parecen ser algunos de los factores que restringen el asilo de efectivos de países musulmanes, a menudo vistos como enemigos (Akkerman, 2018, p. 60), con la aplicación de cuotas (caso sirio). Esta restricción es compartida con la población africana en general. Por el contrario, favorece a grupos cristianos (incluso de zonas de conflicto) y da preferencia a la población iberoamericana.

El discurso mediático, que generalmente juega en contra de los procesos de asilo, interviene en la formación de la percepción, moldeando las opiniones y actitudes políticas de la población de acogida (Ambrosini, 2016, pp. 4-5; Valles, 2016, p. 228).

Los medios de comunicación han creado la idea de que los refugiados son un problema de seguridad (Limón y Fernández, 2016, p. 114) mediante la cobertura negativa de las migraciones forzosas (Rodríguez-Pérez, 2017, p.182). Como indican Fajardo y Soriano (2016, p. 141), los medios construyen un discurso basado en la externalización de las fronteras y el estatus de irregularidad en relación con la política de la UE.

Pero de la misma manera, pueden crear oleadas de solidaridad global, como ocurrió con la publicación (el 2 de septiembre de 2015) de la foto del niño Aylan ahogado en la playa de Bodrum en Turquía, que generó una corriente a favor del asilo para los refugiados sirios. También fue el caso de la llegada de los buques Aquarius (a Valencia el 17 de junio de 2018) o el Open Arms (a Barcelona el 30 de junio de 2018), esta vez creando la controversia entre los que están a favor y en contra de la concesión 
de asilo (Martín, 2019). Aunque los sirios son la primera nacionalidad por número de solicitudes y concesiones de protección en España en 2014 y 2015, en los años siguientes se habla de ellos por encima de los grupos que más crecen (venezolanos, colombianos, salvadoreños, etc.).

Los factores económicos influyen en la aceptación de población inmigrante en general y de los refugiados en particular. La crisis económica internacional de 2008 provocó un retroceso general en la concesión de protección internacional, coincidiendo con el retorno de inmigrantes en situación regularizada (principalmente iberoamericanos) en un contexto de alto desempleo (Aja et al., 2013, p. 13; Arango et al., 2014, p. 5), y con un aumento de la inmigración europea (Bayona-i-Carrasco y Gil-Alonso, p. 15) y hacia Europa (Cebrián et al., 2012, p. 414). Junto con otros factores, la recuperación económica iniciada en 2014 conducirá a un aumento de las solicitudes de protección internacional.

Los factores institucionales y políticos son complejos de analizar, teniendo múltiples relaciones entre sí y con los demográficos, socio-culturales y económicos. La acción de los partidos políticos puede analizarse dado que el período estudiado coincide con la alternancia en el poder del PSOE (socialdemócrata), de abril de 2004 a diciembre de 2011, y del PP (demócrata cristiano), de diciembre de 2011 a junio de 2018 y, de nuevo, con el ascenso del PSOE en esa fecha. Esto permite comparar las políticas de izquierda y de derecha en materia de política de asilo, teniendo en cuenta la coincidencia con la crisis económica internacional.

La Ley de Asilo y Refugio de 2009 fue aprobada con el PSOE en el Gobierno, siendo más restrictiva que la Ley 5/1984, aprobada por el mismo partido. La nueva ley se enmarca en un proceso generalizado en la $\mathrm{UE}$, en plena crisis económica, de endurecimiento de la frontera exterior (Klepp, 2010, p. 2).

El efecto inmediato es un retroceso en las solicitudes de asilo, pero un aumento de las concesiones de protección y un equilibrio entre el estatus de refugiado y la protección subsidiaria. En los años siguientes, cuando la norma incorporó la posibilidad de solicitar protección en la frontera y en los Centros de Internamiento de Extranjeros (CIE) ( $\mathrm{Art}^{\circ}$ 21), las solicitudes aumentaron, pero no se dio un reconocimiento mayor (Morgades, 2014, p. 244). 
Rubén C. Lois-González, Fo Javier Garcia-Delgado Jesús Felicidades-García, María de-la-Rosa-Martínez Origen geográfico de los solicitantes de asilo y concesiones de Protección internacional

en España entre 2008 y 2018

Por otra parte, se estableció la restricción de acceso al territorio español desde los CIE de Ceuta y Melilla a quienes tuvieran una solicitud de asilo tramitada (López-Sala, 2015, p. 185) ${ }^{11}$. A pesar de su importancia, ni los Gobiernos del PSOE ni del PP han desarrollado un reglamento para la aplicación de esta norma (García-Vitoria, 2018, p. 118).

El PSOE sigue una política de escasa protección (2008-2011), que se reduce aún más a partir de 2012 con la llegada del PP al Gobierno, lo que significa, ante el incremento de las solicitudes de protección internacional, una disminución de las concesiones (2012 y 2013, años principales de la política restrictiva).

En 2014, las solicitudes y concesiones se disparan (política de la UE), mientras que éstas vuelven a caer en 2015 (año electoral) y a subir en 2016. La concesión de asilo es muy limitada sobre el total, mientras que la protección subsidiaria es la figura más utilizada, con dominio de la nacionalidad siria (responde a cuotas y reasentamiento), que debe entenderse como protección temporal y revocable, frente al asilo (condición permanente) y que no conduce a la reagrupación familiar (Tax, 2014, p. 27).

Las razones humanitarias responden a la excepcionalidad y rara vez son utilizadas, hasta su desaparición en 2015, como figura por los Gobiernos del PP. Por otra parte, las expulsiones se realizan sin valorar la reagrupación familiar (Montilla et al., 2017, p. 112).

En general, los Gobiernos del PP eliminan la inmigración de la agenda política (Montilla et al., 2017, p. 108), como demuestra la desaparición del Ministerio de Trabajo e Inmigración, que deja al Ministerio de Interior como único interlocutor (Aja et al., 2013, p. 19), convirtiendo la cuestión migratoria y de asilo en una cuestión de seguridad nacional (Limón y Fernández, 2016, p. 114).

Simultáneamente, en el contexto de la crisis económica, se retiraron determinadas prestaciones sanitarias a los extranjeros (Aja et al., 2013, p. 13; Arango et al., 2014, p. 6), lo que supone el fin de la asistencia universal gratuita en España. De esta manera, la política de inmigración y asilo se transforma en un mecanismo de control de fronteras para evitar el «efecto

11 Las solicitudes con frecuencia tratan de evitar la expulsión. Al ser un proceso administrativo, y se admite a trámite en un plazo muy breve, comienzan a darse trabas a las solicitudes, lo que repercute en su retroceso. Las políticas de repatriaciones masivas y devoluciones en caliente también influyen sobre ello. 
llamada», como lo demuestran las escasas concesiones de protección a nacionalidades africanas.

Además, se detecta un efecto ejemplarizante en la denegación a personas procedentes de territorios en estado de guerra y un retroceso en el contexto de crisis humanitarias (brote de ébola de 2013 a 2015). No sucede lo mismo con las nacionalidades somalí, pakistaní, palestina, afgana e iraquí, que han obtenido concesiones a lo largo de todo el período.

En 2018, el Gobierno del PSOE recupera el Ministerio de Trabajo, Migraciones y Seguridad Social con la Dirección General de Integración y Atención Humanitaria ${ }^{12}$, coincidiendo con la apertura de puertos españoles a embarcaciones humanitarias, y con un incremento exponencial de las solicitudes de asilo y de las concesiones (aunque en porcentajes muy por debajo de los años anteriores) y una caída de la protección subsidiaria (en mayor medida que el aumento de refugiados).

Por otro lado, la connivencia con otros Estados, de origen o de tránsito, mediante la firma de acuerdos múltiples y diferentes instrumentos (Gabrielli, 2017, p. 128) y la consideración de terceros países como «seguros» (Rais, 2016, p. 46), aparece como factor político-institucional en el contexto comunitario.

Este hecho está ligado a los procesos de externalización de fronteras (Valles, 2016, p. 227; Gabrielli, 2017; p. 128) y de desterritorialización de las fronteras exteriores a terceros (Naranjo, 2014, p. 15) con el fin de controlar el flujo hacia los países de tránsito. Un ejemplo de ello es el acuerdo hispano-marroquí de readmisión de inmigrantes (1992), que desde 2005 permite «devoluciones en caliente» en las vallas de Ceuta y Melilla (González, 2017, p. 19) tanto por los Gobiernos del PSOE como del PP.

También se manifiesta en la firma de acuerdos sobre inmigración ilegal con 14 gobiernos subsaharianos en los denominados Planes África (2000-2010), que implican acuerdos de readmisión y de otro tipo (Azkona, 2013; Gabrielli, 2017, p. 129). La mayoría de estos acuerdos se realizan con países con claras deficiencias democráticas (Gabrielli, 2017, p. 143).

El primer efecto será la escasa incidencia de solicitudes de ciudadanos marroquíes y el alto grado de rechazo de sus solicitudes, así como las de otras nacionalidades africanas. Asimismo, la consideración de algunos

12 El último gobierno de coalición PSOE-Unidas Podemos (enero de 2020) crea una Secretaría de Estado de Migraciones, dentro del Ministerio de Inclusión, Seguridad Social y Migraciones. 
Rubén C. Lois-González, Fo Javier Garcia-Delgado Jesús Felicidades-García, María de-la-Rosa-Martínez Origen geográfico de los solicitantes de asilo y concesiones de Protección internacional

en España entre 2008 y 2018

de estos países como seguros (Marruecos), motiva tanto las devoluciones en caliente (Arango et al., 2016, p. 12) como las restricciones de acceso de refugiados en España, que no se materializan en solicitudes de asilo a pesar de la existencia, en muchos casos, de razones objetivas.

La política exterior de cada Gobierno tendrá un efecto directo sobre las nacionalidades a las que se les concede protección. Un caso paradigmático es el cubano. Tanto el acercamiento del PSOE como el distanciamiento del PP en las relaciones bilaterales se han materializado en la aceptación de la protección a cubanos, con un incremento en la concesión de protección en 2011 y 2012, en plena crisis económica.

Sin embargo, Cuba deja de ser un objetivo prioritario desde 2013 (aceptación de presos políticos), debido a la reorientación de la política exterior (crisis humanitaria de Siria) y del escenario internacional (política de la administración Obama hacia la isla). En este contexto se enmarca también la aceptación de ciudadanos ecuatoguineanos hasta 2012.

En el caso palestino, es la política de Estado la que justifica el asilo por solidaridad, siendo el principal en concesiones de asilo (17,04\% del total), aunque con altibajos (máximo en 2015, procedentes de campos de refugiados de Siria). Habría que añadir la política para Oriente Próximo y la cooperación española (en 2014 se registra una proposición no de ley de reconocimiento de un Estado palestino).

Aunque la política de asilo española se sitúa en el contexto de la UE (Morgades, 2014, p. 228), la falta de una política común hace que existan diferencias sustanciales en cada país (Mecoleta, 2002, p.93; Galeote, 2009, p. 68; Nancheva, 2015, p. 1; Morgades, 2014, p. 228; Pérez-Villalobos, 2017, pp. 23-24). De hecho, la mejora y armonización de las normas no han contribuido a la protección satisfactoria de los refugiados, sino al progresivo deterioro (Bačić, 2012, p. 42) y al avance de una política restrictiva (Belloso, 2016b, p. 101).

Se trata de una cuestión de soberanía nacional (Mangas, 2016, p. 1) plasmada en una política comunitaria. Desde 2013 existe una crisis de refugiados, en la que la política comunitaria de asilo se centra en la seguridad, lo que significa la puesta en marcha de operaciones militares (RamónChornet, 2015, p. 254) que no solucionan, por inoperancia e ineficacia, el problema de los refugiados (Fernández-Huertas y Rappaport, 2015, p. 10; Pérez-Villalobos, 2017, p. 5). 
Se habla de «securitización migratoria» hacia el sur (Ríos-Vargas, 2015, p. 51), con una «quiebra de la solidaridad» en las políticas europeas (Arango, 2016, p. 37). Se trata del diseño de la «Fortaleza Europa» (Marfleet, 1999, p. 70; Cyrus, 2008, p. 179; Hansen, 2008, p. 251), en la que los más solidarios son los que tienden a integrar las políticas de asilo (Spehar, 2012, p. 1).

Así lo demuestran los Acuerdos con Turquía de 18 de marzo de 2016 (Belloso, 2016b, 91), en los que Turquía aprovecha para forzar las negociaciones de adhesión con la UE (Mangas, 2016, pp. 5-6). En parte, la crisis de los refugiados es consecuencia de la falta de armonización legislativa y de la ausencia de cultura de refugio en los países mediterráneos (Consoli, 2015, p. 14).

El aumento en la protección de 2012 a 2016 debe enmarcarse en la crisis de los refugiados, pero especialmente en la europeización de la política de asilo (Spehar, 2012, p. 7), con la implantación de cuotas en la UE a partir de 2015, defendidas por Estados tradicionalmente solidarios como Suecia y Alemania (Fargues, 2014, p. 2).

Ante la crisis humanitaria, para evitar devoluciones, se establece la reubicación o reasentamiento (Arenas-Hidalgo, 2016, p. 358), con la Decisión 2015/1523 del Consejo, que establece un cupo de 40.000 personas en 2 años, y la Decisión 2015/1601, con 120.000 más hasta septiembre de 2017 (Arenas-Hidalgo, 2016, p. 363), lo que abre la posibilidad de que otro país analice la solicitud de protección.

El Tratado de Ámsterdam (1999) había regulado por separado las afluencias masivas y repentinas (Mangas, 2016, p. 6), lo que fue recogido en la Directiva 2001/55, que estableció la obligación de los Estados miembros de recibir en los casos graves, pero no decía cómo distribuirlos, por lo que no se respetaron las cuotas (Arenas-Hidalgo, 2016, p. 364).

Así, el cumplimiento de esas cuotas ha sido desigual (Romano, 2018, p. 269) y se considera un fracaso (Arango, 2016, p. 39). De hecho, supone el fin del Régimen de Dublín (a la hora de evaluar solicitudes de personas procedentes de otro Estado europeo) y la crisis de la gobernanza europea (Ferrero-Turión, 2016b, pp. 164-165).

El establecimiento de cuotas determinará el incremento de las solicitudes en el caso de ciudadanos sirios en España como resultado del reasentamiento (fundamentalmente de Grecia e Italia) (Romano, 2018, p. 
Rubén C. Lois-González, Fo Javier Garcia-Delgado Jesús Felicidades-García, María de-la-Rosa-Martínez Origen geográfico de los solicitantes de asilo y concesiones de Protección internacional

en España entre 2008 y 2018

270), que reciben mayoritariamente protección subsidiaria. Así, los sirios se convierten en los principales solicitantes de protección internacional en 2014 y 2015, lo que coincide en parte con el acceso a través de Melilla e implica el reasentamiento de refugiados.

El Gobierno del PP pasa del «no podemos» al «deber legal» (GarcésMascareñas, 2016, p. 322), pero a pesar del aumento conocido, la cuota de refugiados no se cumple: a 26 de septiembre de 2017, de 17.337 personas España acoge 1.980 (Montilla et al., 2017, p. 109).

Como resultado, los sirios se ven favorecidos frente a afganos, iraquíes, iraníes, palestinos y pakistaníes, mientras que los africanos se quedan por detrás de los asiáticos. El incremento de 2017 y 2018 se debe a las políticas del nuevo Gobierno español, con la recepción de barcos de inmigrantes, pero los mayores incrementos de solicitudes se localizan entre ciudadanos americanos (Venezuela, Colombia, Honduras, El Salvador y Nicaragua), países africanos (Argelia, Marruecos, Mali) y asiáticos (Palestina), mientras que los sirios tienden a disminuir en 2018, al igual que los ucranianos.

El último factor externo a considerar es el electoralismo, relacionado con el discurso mediático y la percepción de la población. Los refugiados ocupan portadas de los periódicos y afectan en el resultado de las elecciones (Ambrosini, 2016, p. 15). El auge del populismo y el nacionalismo (Maihold, 2018, p. 171) es un cóctel que combina contexto socioeconómico, multiculturalismo e Islam (Kaya, 2017, pp. 74-75).

Hasta finales de 2018, España era un país donde los movimientos de extrema derecha, xenófobos y antiinmigración eran ajenos a la representación parlamentaria, hasta que entraron por primera vez en el Parlamento Andaluz, y después en el Congreso de los Diputados en abril de 2019.

En esta última campaña electoral también hubo un discurso a favor de restringir la inmigración (y la protección internacional) no solo por parte de la ultraderecha, sino también del PP y Ciudadanos (conservadores y liberales), como ha ocurrido en otros países europeos (CSU en Alemania, estudiado por Arango, 2016). La relación entre el electoralismo y el retroceso de las políticas de asilo del PP fue evidente en 2015, año electoral, cuando las concesiones cayeron en plena crisis de los refugiados. 


\section{Conclusiones}

A lo largo del período se ha observado que España es un país en el que las solicitudes de protección internacional son escasas, y aunque existe una tendencia al incremento, ésta no se corresponde en términos porcentuales con el aumento de las concesiones de protección internacional.

Se han producido cambios en el número y procedencia (multiplicación) de las solicitudes de protección internacional, con el desplazamiento desde países americanos a otros de Asia y África, aunque en los últimos dos años ha habido un importante crecimiento de solicitudes procedentes del continente americano, debido a crisis internas (Venezuela) y a las restricciones impuestas por el Gobierno de Trump.

Los conflictos armados y el estado de guerra (Siria, Irak, Mali), la inestabilidad interna (Pakistán, Afganistán) y las crisis humanitarias (Venezuela) subyacen a estos cambios. Pero también se pueden observar el efecto frontera (acceso desde África: Argelia, Nigeria, Mali) y el efecto llamada (ucranianos, colombianos, venezolanos).

Los medios de comunicación magnifican el asilo y crean opinión, que se manifiesta en el electoralismo y en la propensión o no hacia grupos de asilados. En general, el miedo aparece como elemento cohesionador contra los refugiados, que se materializa en las políticas restrictivas de los Gobiernos de derechas, mientras que los de izquierda valoran la solidaridad, que genera cierto efecto llamada, pero no especialmente entre los orígenes que reciben protección internacional.

El derecho de asilo es una figura que ha sido instrumentalizada en las políticas estatales en función de factores externos, de manera que son los factores internos y las causas los que trasladan la solicitud a un segundo plano. Así, frente a la multiplicación de las nacionalidades solicitantes, se produce una concentración de las concesiones, lo que indica que son las directrices políticas del partido gobernante las que condicionan el asilo, con la excepción de la acción de la política comunitaria de cuotas (incumplida) y de la política de Estado. Pero las condiciones de protección internacional empeoran de forma generalizada, porque «la solidaridad tiene un precio». 
Rubén C. Lois-González, Fo Javier Garcia-Delgado Jesús Felicidades-García, María de-la-Rosa-Martínez Origen geográfico de los solicitantes de asilo y concesiones de Protección internacional

en España entre 2008 y 2018

\section{Referencias}

Abu-Warda, N. (2007). Las migraciones internacionales. El Islam en Europa hoy. Anejo XXI, 'Ilu. Revista de Ciencias de las Religiones, pp.33-50.

ACNUR-España (2018). Datos básicos. $<$ https://www.acnur.org/datos-basicos.html>

Aja, E., Arango, J. \& Alonso, J. O. (2013). Crisis, mercado de trabajo y cambiantes tendencias migratorias. Anuario CIDOB de la Inmigración, pp. 9-24.

Akkerman, T. (2018). Partidos de extrema derecha y políticas de inmigración en la UE. Anuario CIDOB de la Inmigración, pp. 48-62.

Ambrosini, M. (2014). Better than our fears? Refugees in Italy: between rhetorics of exclusion and local projects of inclusion. Refugee protection and the role of law: Conflict in identities, pp. 235-250.

Ambrosini, M. (2016). Refugiados y otros inmigrantes en Italia:¿Por qué algunos nos aterrorizan y los demás se instalan sin mayores problemas? Migración y desarrollo, 14(27), pp. 3-18.

Andreatta, A. (2017). Libia tras la primavera árabe. Una senda hacia Europa entre narcoterrorismo y Refugiados (2011-2016). In La fortaleza de Europa: Vallas y Puentes. XIII Congreso AECPA, 20 a 22 septiembre 2017. Santiago de Compostela.

Apostolovska, B., Madjevikj, M. \& Ljakoska, M. (2018). Contemporary migration movements among Macedonia and the Balkan countries. In Jovana Brankov \& MarijaDrobnjaković (Ed.). The Balkan peninsula of Jovan Cvijic: historical background and contemporary trends in Human Geography. Proceedings of the International Conference held in Tršić Loznica, October 29-30, 2018, Belgrad and Loznica, pp. 137-151.

Arango, J. (2016). A través del Mediterráneo: tragedia de los refugiados y crisis de la UE. Anuario CIDOB de la Inmigración, pp. 30-55.

Arango, J., Mahía, R., Malapeira, D. M. \& Sánchez-Montijano, E. (2017). Introducción: La inmigración en el ojo del huracán. Anuario CIDOB de la Inmigración, pp. 12-28.

Arango, J., Mahía, R., Moya, D. \& Sánchez-Montijano, E. (2016). Introducción. El año de los refugiados. Anuario CIDOB de la Inmigración, pp. 12-26. 
Arango, J., Malapeira, D. M. \& Alonso, J. O. (2014). 2013: ¿Un año de transición?.Anuario CIDOB de la Inmigración, pp. 9-24.

Arenas-Hidalgo, N. (2016). Flujos masivos de población y seguridad. La crisis de personas refugiadas en el Mediterráneo. Araucaria, 18(36). Aubarell, G. (2005). Inmigración en el espacio euromediterráneo. Documentos. Proceso euromediterráneo e inmigración.

Azkona, N. (2013). La coherencia de los Planes África a examen: La relación entre los flujos de migración y los fondos de cooperación al desarrollo entre África Occidental y la Unión Europea (Tesis Doctoral). Universidad del País Vasco.

Bačić, N. (2012). Asylum policy in Europe-the competences of the European Union and inefficiency of the Dublin system. Croatian yearbook of European law \& policy, 8(8), pp. 41-76.

Bayona-i-Carrasco, J. \& Gil-Alonso, F. (2016). Europeos bajo la crisis: cambios en sus patrones migratorios recientes en España. Scripta Nova, Revista de Geografia y Ciencias Sociales, XX, pp. 549-552.

Belloso, N. (2016a). ¿La globalización de la indiferencia? algunas reflexiones sobre los desplazados, los migrantes y los refugiados en la Unión Europea. Revista do Direito, 3(50), pp. 139-174.

Belloso, N. (2016b). The refugee crisis in the European Union: the background jusphilosophical. In Unoesc International Legal Seminar. Vol. 4, No. 1, pp. 91-112.

Borja, A. (2017). ¿Refugiados de primera o segunda clase? Relaciones Internacionales (36), pp. 31-50.

Borrás, S. (2006). Refugiados ambientales: el nuevo desafío del derecho internacional del medio ambiente. Revista de derecho (Valdivia), 19(2), pp. 85-108.

Camacho, A. F. (2017). Efectos de la migración forzada sobre la confianza y las actitudes hacia inmigrantes en los países destino: evidencia de la crisis de refugiados en Europa (No. 015704), Universidad de Los Andes-CEDE.

Comisión española de Ayuda al Refugiado (CEAR) (2018). Las personas refugiadas en España y Europa, Comisión española de Ayuda al Refugiado. Madrid.

Cebrián, J. A., Bodega, M. I. \& Martín-Lou, M. A. (2012). Inmigraciones en Europa. Estudios Geográficos, 73(273), pp. 385-419. 
Rubén C. Lois-González, Fo Javier Garcia-Delgado Jesús Felicidades-García, María de-la-Rosa-Martínez Origen geográfico de los solicitantes de asilo y concesiones de Protección internacional

en España entre 2008 y 2018

Cebrián, M. (2009). Los determinantes de los flujos migratorios internacionales: el caso español, 1995-2007. Principios: estudios de economía política, (14), pp. 49-68.

Charsley, K. \& Wray, H. (2015). Introduction: the invisible (migrant) man. Men and Masculinities, 18(4), pp. 403-423.

Chin, A. \& Cortes, K. E. (2015). The refugee/asylum seeker. In Handbook of the economics of international migration. North-Holland. Vol. 1, pp. 585-658.

Consoli, M. T. (2015). Migrations towards Southern Europe. The case of Sicily and the Separated Children: The case of Sicily and the Separated Children. Franco Angeli.

Constantinescu, M. (2004). The importance of reference system in international migration: the duality origin country-destination country or system perspective? Retrieved, 5(21), 2008.

Cwerner, S. B. (2004). Faster, faster and faster: the time politics of asylum in the UK. Time \& Society, 13(1), pp. 71-88.

Cyrus, N. (2008). Being illegal in Europe: Strategies and policies for fairer treatment of migrant domestic workers. Migration and Domestic Work. A European Perspective in a Global Theme, pp. 177-194.

Díez, J. (2015). Yihadismo en África: amenaza, contexto y respuesta. Análisis del Instituto Español de Estudios Estratégicos. Documento de Análisis 10/2015.

Eurostat (2019). Asylum and first time asylum applicants by citizenship, age and sex Annual aggregated data (rounded) [migr_asyappctza] $<$ http://ec.europa.eu/eurostat/web/asylum-and-managed-migration/ data/database $>$.

Fajardo, R. \& Soriano, R. M. (2016). La construcción mediática de la migración en el Mediterráneo: ¿no-ciudadanía en la prensa española? Revista Internacional de Estudios Migratorios, 6(1), pp. 141-169.

Fargues, P. (2014). Europe must take on its share of the Syrian refugee burden, but how? Migration Policy Centre, 14 February 2014. European University Institute.

Fernández-Huertas Moraga, J. \& Rapoport, H. (2015). Tradable refugee-admission quotas and EU asylum policy. CESifo Economic Studies, 61(3-4), pp. 638-672. 
Ferrero-Turrión, R. (2016). Seguridad y derechos humanos, la crisis de refugiados como crisis de valores de la UE. bie3: Boletín IEEE, (1), pp. 385-395.

Freedman, J. (2012). Taking gender seriously in Asylum and refugee policies. In Global Migration.Palgrave Macmillan, New York, pp. 45-64.

Gabanes, A. (2014). Lo que envuelve al refugiado: generando desplazamientos forzados por medio de la violencia. Estudios Humanísticos. Historia, (13), pp. 187-210.

Gabanes, A. (2015). Lo que envuelve al refugiado: generando desplazamientos forzados por medio de la violencia. Estudios Humanisticos. Historia, (13), pp. 187-210.

Gabrielli, L. (2017). La externalización europea del control migratorio ¿La acción española como modelo? Anuario CIDOB de la Inmigración, pp. 126-152.

Galeote, G. (2009). El derecho de asilo en España y en Francia: entre margen de discrecionalidad y margen de actuación. Pandora: revue d'etudes hispaniques, (9), pp. 53-70.

Garcés-Mascareñas, B. (2016). Fuera de campaña electoral: devoluciones en caliente, refugiados e inmigrantes irregulares. Anuario CIDOB de la Inmigración, pp. 320-337.

García-Delgado F.J., Felicidades-García J., Lois-González R.C. \& DeLa-Rosa-Martínez M. (2019). Causes and Factors in the Granting of International Protection to Asylum Applicants in Spain Between 2008 and 2016.International Journal of Anthropology, 32 (3-4), pp. 85-110.

García-Vitoria, I. (2018). Una década sin reglamento de asilo en España: obstáculos e interpretaciones divergentes. Anuario CIDOB de la Inmigración, pp. 116-128.

Gobierno de España (1978). Instrumento de Adhesión de España a la Convención sobre el Estatuto de los Refugiados, hecha en Ginebra el 28 de julio de 1951, y al Protocolo sobre el Estatuto de los Refugiados, hecho en Nueva York el 31 de enero de 1967.

Gobierno de España (1984). Ley 5/1984, de 26 de marzo, reguladora del derecho de asilo y de la condición de refugiado.

Gobierno de España (2009). Ley 12/2009, de 30 de octubre, reguladora del derecho de asilo y de la protección subsidiaria. 
Rubén C. Lois-González, Fo Javier Garcia-Delgado Jesús Felicidades-García, María de-la-Rosa-Martínez Origen geográfico de los solicitantes de asilo y concesiones de Protección internacional

en España entre 2008 y 2018

Goldner-Lang, I. (2013). Is There Solidarity on Asylum and Migration in the EU? Croatian yearbook of European law \& policy, 9(9), pp. 1-14. González, M. \& Aguilera, M. (2000). Los países del Este nuevo foco de emigración de la Europa actual. Su incidencia en España. Estudios geográficos, 61, pp. 257-282.

González-García, I. (2017). Rechazo en las fronteras exteriores europeas con Marruecos: inmigración y derechos humanos en las vallas de Ceuta y Melilla, 2005-2017. Revista General de Derecho Europeo, 43(2), pp. 17-57.

Gray, C. L. (2010). ¿Refugiados medioambientales o emigrantes económicos? Population Reference Bureau.

Guasch, C. (2010). Menores no acompañados ante la protección internacional del asilo. Educación social: Revista de intervención socioeducativa, (45), pp. 78-92.

Hansen, P. (2008). EU: migrations politik under 50 år. Ett integrerat perspektiy påenotsägel sefull ut veckling. Studentlitteratur: Malmö AB.

Hatton, T. J. (2016). Refugees, asylum seekers, and policy in OECD countries. American Economic Review, 106(5), pp. 441-445.

Hatton, T. J. \& Williamson, J. G. (2006). Refugees, asylum seekers, and policy in Europe. In Labor mobility and the world economy. Springer, Berlin, Heidelberg, pp. 249-284.

Hofmann, E. T., Jacobs, P. \& Petrzelka, P. (2019). State Immigration Policies: The Role of State Compacts and Interest Groups on Immigration Legislation. International Migration, 57(1), pp. 109-126.

Holzer, T., Schneider, G. \& Widmer, T. (2000). The impact of legislative deterrence measures on the number of asylum applications in Switzerland (1986-1995). International Migration Review, 34(4), pp. 1.182-1.216.

ILGA (2019). Mapas-Legislación sobre orientación sexual. $<$ https://ilga. org/es/mapas-legislacion-sobre-orientacion-sexual>

INE (2019). Padrón Continuo. Instituto Nacional de Estadística. $<$ http:// ine.es/dyngs/INEbase/es/operacion.htm?c=Estadistica_C\&cid=125 4736177012\&menu $=$ ultiDatos\&idp $=1254734710990>$

Kaya, A. (2017). Populismo e inmigración en la Unión Europea. Anuario CIDOB de la inmigración, pp. 52-79. 
Klepp, S. (2010). A contested asylum system: The European Union between refugee protection and border control in the Mediterranean Sea. European Journal of Migration and Law, 12(1), pp. 1-21.

Limón, P. \& Fernández, L. (2016). De los valores civilizatorios a las fronteras del miedo: la conversión mediática de los refugiados en un problema para la seguridad europea. Documentación social, (180), pp. 111-126.

López-Sala, A. (2015). La inmigración irregular en Ceuta y Melilla en 2014: prácticas de control y debate público. Anuario $C I D O B$ de la Inmigración, pp. 169-192.

Lueck, K., Due, C. \& Augoustinos, M. (2015). Neoliberalism and nationalism: Representations of asylum seekers in the Australian mainstream news media. Discourse \& Society, 26(5), pp.608-629.

Maihold, G. (2018). Migración, control de fronteras y acuerdos migratorios de la Unión Europea con terceros países. Revista Mexicana de Política Exterior, 112, pp. 161-183.

Mallett, R. \& Hagen-Zanker, J. (2016). El papel de la comunidad en los viajes de los refugiados a Europa. Revista Migraciones Forzadas, pp.53-57.

Malloch, M. S. \& Stanley, E. (2005). The detention of asylum seekers in the UK: Representing risk, managing the dangerous. Punishment \& Society, 7(1), pp. 53-71.

Mangas, A. (2016). Protección internacional y europea ante afluencias masivas de refugiados. Economía Exterior, 75, pp. 1-8.

Manzanedo, C. \& Forina, A. (2016). « ¡Todavía no!». Una perspectiva desde los refugiados. Documentación social, 180, pp. 223-239.

Marfleet, P. (1999). Nationalism and internationalism in the new Europe. International Socialism Journal, 84, pp. 96-100.

Martín, M. (2019). "El Gobierno deniega el asilo a rescatados por el Aquarius". El País. <https://elpais.com/politica/2019/09/27/actualidad/1569610731_776092.html>

Martínez, R. M. \& Golías, M. (2005). La latinoamericanización de la inmigración en España. Cuadernos geográficos de la Universidad de Granada, 36(1), pp. 51-64.

Mecoleta, A. (2002). Asilo y refugio en la Unión Europea: España y el Reino Unido. Puentes, 2, pp. 93-101. 
Rubén C. Lois-González, Fo Javier Garcia-Delgado Jesús Felicidades-García, María de-la-Rosa-Martínez Origen geográfico de los solicitantes de asilo y concesiones de Protección internacional

en España entre 2008 y 2018

MI (2008-2018). El asilo en cifras. Ministerio del Interior. <http://www. interior.gob.es/web/archivos-y-documentacion/documentaciony-publicaciones/publicaciones-descargables/extranjeria-y-asilo/ asilo-en-cifras>

Montilla, J., García-Vitora, I. \& Rodríguez, J. L. (2017). Política y normativa española sobre inmigración y asilo ¿Bajo perfil o inacción? Anuario CIDOB de la Inmigración, pp. 106-122.

Moreno, I. M. \& López, G. (2006). Los determinantes de la inmigración internacional en España. Investigaciones regionales: Journal of Regional Research, (9), pp. 25-48.

Morgades, S. (2014). La política de asilo en España en el contexto europeo: cambios recientes y perspectivas de desarrollo normativo. Anuario CIDOB de la Inmigración, pp. 225-248.

Nancheva, N. (2015). The Common European Asylum System and the failure to protect: Bulgaria's Syrian refugee crisis. Southeast European and Black Sea Studies, 15(4), pp. 439-455.

Naranjo, G. E. (2014). Desterritorialización de fronteras y externalización de políticas migratorias. Flujos migratorios irregulares y control de las fronteras exteriores en la frontera España-Marruecos. Estudios Políticos, (45), pp. 13-32.

ONU (1951). Convention Relating to the Status of Refugees (Geneva Convention), Ginebra.

ONU (1967). Protocol Relating to the Status of Refugees New York, 31 january 1967. Nueva York.

Padilla, B. \& Goldberg, A. (2017). Dimensiones reales y simbólicas de la" crisis de refugiados" en Europa: un análisis crítico desde Portugal. REMHU-Revista Interdisciplinar da Mobilidade Humana, 25(51), pp. 11-27.

Pérez-Villalobos, M. C. (2017). La crisis de los refugiados y el Derecho de Asilo en la Unión Europea. Anales de Derecho, 35 (1).

Peters, M. A. \& Besley, T. (2015). The Refugee Crisis and The Right to Political Asylum. Educational Philosophy and Theory, pp. 1.367-1.374.

PNUD (2017). Panorama general Informe sobre Desarrollo Humano 2016 Desarrollo humano para todos. PNUD. Nueva York. 
Prieto, C. A. (2013). La situación de las migraciones internacionales mixtas, un desafío constante para el derecho internacional de los refugiados y el derecho de asilo. Díkaion, 22(1), pp. 83-107.

Rais, M. (2016). European Union readmission agreements. Forced Migration Review (51), pp. 45-46.

Ramón-Chornet, C. (2015). Sobre el impacto de la crisis de refugiados en la PCSD de la Unión Europea Referencia a la contribución de España. Anuario Español de Derecho Internacional (31), pp. 241-264.

Ríos-Vargas, A. D. (2015). Marruecos y México: dos modelos de securitización migratoria en las fronteras de la globalización. Ciencia UAT, 10(1), pp. 47-55.

Rodríguez-Pérez, C. (2017). Enfoques de las noticias y legitimidad mediática: estudio exploratorio de la cobertura de la crisis de refugiados en la Unión Europea. Comunicación y Sociedad, 30(3), pp. 169-184. Romano, A. (2018). Los programas de reasentamiento de refugiados en la UE: tendencias actuales y repercusiones en España. Anuario CIDOB de la Inmigración, pp.262-282.

Schuster, L. (2005). The Realities of a New Asylum Paradigm (Report No.WP-05-20). Oxford, UK: University of Oxford, Centre on Migration, Policy and Society (COMPAS).

Spehar, A. (2012). Reducing Refugee Numbers through European Integration? Swedish Party Politics and the Harmonisation of the European Asylum Policy. Cergu's working paper series, 7.

Tax, B. (2014). Refugiados por asociación. Revista Migraciones Forzadas, 47, pp. 26-27.

Triandafyllidou, A. \& Mantanika, R. (2017). Emergencia de refugiados en el Mediterráneo: evaluación de las respuestas políticas de la Unión Europea. Migración y desarrollo, 15(28), pp. 7-38.

Türk, V. (2013). Garantizar la protección para las personas de interés LGBTI. Revista Migración Forzada, 42, pp. 5-8.

Unión Europea (U E) (2001). Directiva 2001/55/CE del Consejo de 20 de julio de 2001 relativa a las normas mínimas para la concesión de protección temporal en caso de afluencia masiva de personas desplazadas y a medidas de fomento de un esfuerzo equitativo entre los Estados miembros para acoger a dichas personas y asumir las consecuencias de su acogida. 
Unión Europea (UE). (2007). Report from the Commission to the European Parliament and the Council on the implementation of Regulation (EC) No 862/2007 on Community statistics on migration and international protection.

Unión Europea (UE). (2013). Reglamento (UE) no 604/2013 del Parlamento Europeo y del Consejo de 26 de junio de 2013: por el que se establecen los criterios y mecanismos de determinación del Estado miembro responsable del examen de una solicitud de protección internacional presentada en uno de los Estados miembros por un nacional de un tercer país o un apátrida (Texto refundido).

Valles, M. (2015). ¿Vallas al asilo? Apuntes sobre el sistema de protección internacional en España. Anuario CIDOB de la inmigración, 20152016, pp. 226-245.

Valles, M. (2016). ¿Vallas al asilo? Apuntes sobre el sistema de protección internacional en España. Anuario CIDOB de la inmigración, 20152016, pp. 226-245.

Vink, M. \& Engelmann, C. (2012). Informal European asylum governance in an international context. In Hrsg. Thomas Christiansen \& Christine Neuhold International Handbook on Informal Governance, pp. 690-718. Cheltenham: Edward Elgar. 
